\title{
Catastrophic consequences: can the feline parasite Toxoplasma gondii prompt the purrfect neuroinflammatory storm following traumatic brain injury?
}

Tamara L. Baker', Mujun Sun ${ }^{1}$, Bridgette D. Semple ${ }^{1,2}$, Shiraz Tyebji ${ }^{3}$, Christopher J. Tonkin ${ }^{3}$, Richelle Mychasiuk ${ }^{1}$ and Sandy R. Shultz ${ }^{1,2^{*}}$ (D)

\begin{abstract}
Traumatic brain injury (TBI) is one of the leading causes of morbidity and mortality worldwide; however, treatment development is hindered by the heterogenous nature of TBI presentation and pathophysiology. In particular, the degree of neuroinflammation after TBI varies between individuals and may be modified by other factors such as infection. Toxoplasma gondii, a parasite that infects approximately one-third of the world's population, has a tropism for brain tissue and can persist as a life-long infection. Importantly, there is notable overlap in the pathophysiology between TBI and T. gondii infection, including neuroinflammation. This paper will review current understandings of the clinical problems, pathophysiological mechanisms, and functional outcomes of TBI and T. gondii, before considering the potential synergy between the two conditions. In particular, the discussion will focus on neuroinflammatory processes such as microglial activation, inflammatory cytokines, and peripheral immune cell recruitment that occur during $T$. gondii infection and after TBI. We will present the notion that these overlapping pathologies in TBI individuals with a chronic T. gondii infection have the strong potential to exacerbate neuroinflammation and related brain damage, leading to amplified functional deficits. The impact of chronic $T$. gondii infection on TBI should therefore be investigated in both preclinical and clinical studies as the possible interplay could influence treatment strategies.
\end{abstract}

Keywords: Parasite, Infection, Neuroinflammation, Immune response, Microglia, Astrocytes

\section{Background}

Traumatic brain injury (TBI) is a leading cause of morbidity and mortality worldwide, yet there have been no successful phase III TBI clinical trials to date [1-3]. To develop effective TBI interventions, it is imperative that we understand the underlying mechanisms that drive

\footnotetext{
* Correspondence: sandy.shultz@monash.edu

'Department of Neuroscience, Monash University, 6th Floor, The Alfred Centre, 99 Commercial Road, Melbourne, VIC 3004, Australia

${ }^{2}$ Department of Medicine, The University of Melbourne, Parkville, VIC, Australia

Full list of author information is available at the end of the article
}

negative outcomes, as well as the factors that can modify TBI pathophysiology [4, 5]. For example, neuroinflammation is recognized as a key secondary injury mechanism in TBI, and initial studies indicate that the presence of concurrent immune stressors can alter the aftermath of TBI [6-9]. However, despite the important implications of this phenomenon in understanding TBI heterogeneity and optimizing interventions, it remains an understudied topic [10].

One possible mechanism that can contribute to neuroinflammation is an underlying infection. Toxoplasma gondii is a parasite that infects approximately one-third 
of the world's population [11]. In other words, many people who sustain a TBI are likely already infected with $T$. gondii at the time of injury. T. gondii has a tropism for brain tissue in intermediate hosts such as rodents and humans, and through the development of cysts, chronic life-long infection ensues [11]. Notably, there is significant overlap between the pathophysiology of $T$. gondii and TBI, including the activation of similar neuroinflammatory pathways $[12,13]$. Considering the prevalence and pathophysiological similarities of TBI and $T$. gondii, it is important to consider the potential impact of T. gondii infection on TBI outcomes and appropriate intervention strategies. However, to our knowledge, the effect of $T$. gondii on TBI outcomes has never been studied. Therefore, this review will highlight the clinical problems, neuroinflammatory pathways, and functional consequences of TBI and T. gondii separately, before discussing the potential synergistic effects of $T$. gondii infection in individuals who have sustained a TBI. We conclude by emphasizing the need for further research into this relationship and provide suggestions for future studies.

\section{Traumatic brain injury \\ Clinical problem of TBI}

TBI is a key contributor to the global burden of disease $[2,14]$. Reported incidence rates per country markedly vary depending on case definition, and are influenced by a lack of diagnosis, reporting, and medical attention being sought for mild TBI individuals [15-17]. Globally, estimates of annual incidence range from 47.3 to 1322/ 100,000 depending on region, with most estimates throughout the Western world being placed around 250-350/100,000 [2, 18]. This equates to between 10 and 27 million new cases of TBI each year worldwide; however, this is believed to be an underestimation [15]. Furthermore, since 1990, there has been an increase of $77 \%$ in the absolute number of disability-adjusted lifeyears as a result of TBI [19]. This emphasizes not only the lasting impact of a TBI but also the extent to which this global health burden continues to grow. Additionally, TBI is associated with the development of neurological and mental disorders such as post-traumatic epilepsy (PTE) [20], major depressive disorder [21], and schizophrenia [22], while also being a risk factor for neurodegenerative diseases including Alzheimer's disease (AD) [23] and Parkinson's disease [24].

Despite promising pre-clinical and phase II clinical trials in TBI, to date, no phase III clinical trial has identified a therapy that improves TBI recovery $[1,3]$. This reflects not only the barrier posed by the heterogenous nature of TBI pathophysiology and presentation but also the juxtaposition of variability seen within preclinical and clinical study designs. In a clinical setting, TBI varies in injury mechanism and severity, as well as pre-injury vulnerabilities such as age, sex, and genetic factors [4]. Pre-injury vulnerabilities, or even the presence of other concurrent factors such as infection, may alter TBI pathophysiology and outcomes [5, 10, 25-27]. On the other hand, preclinical animal models, which ultimately provide the foundation for clinical trials, are highly homogenous as they typically utilize isolated TBI platforms that often fail to incorporate the heterogeneity of the clinical population [4]. This discrepancy demonstrates the necessity to expeditiously study TBI pathophysiology, the clinical factors that modify it, and develop implementable intervention strategies.

\section{TBI pathophysiology}

\section{Primary mechanisms}

The neurological damage associated with TBI may result from a range of pathophysiological mechanisms. 'Primary injury' is the result of direct mechanical forces, most commonly resulting from falls, motor vehicle accidents, assaults, and war zone injuries [2, 18, 28]. These direct forces can lead to the rapid onset of largely irreversible mechanical disruptions to brain tissue. Such disruptions may include direct cell death, torn or stretched axons, and damage to the blood-brain barrier (BBB), all of which are considered to be hallmarks of TBI [29-31].

As a result of the mechanical insult, neurons can sustain damage that leads to ionic flux and inappropriate depolarization [32]. For example, neurons become depolarized resulting in an influx of calcium to the presynaptic cell, causing a large release of the excitatory neurotransmitter glutamate, into the synaptic cleft [33]. This release has been shown through microdialysis studies in both humans and rodents to occur in a forcedependent manner, within minutes of sustaining a TBI [34-36]. Glutamate then acts on $\alpha$-amino-3-hydroxy-5methyl-4-isoxazole-propionic acid and $N$-methyl-D-aspartate receptors on the post-synaptic neuron, leading to increased calcium entry [33]. Increased intracellular calcium can further lead to intermediate early gene activation, disruption of mitochondrial production of adenosine triphosphate (ATP), activation of proteases and kinases, and increased production of reactive oxygen species (ROS) [37]. Increased extracellular glutamate can result in decreased expression of glutamate (GLT)-1 or excitatory amino acid transporter-2 transporters on astrocytes [38]. This can cause glutamate to remain in the synaptic cleft resulting in excitotoxicity, which can then lead to further cell death, neuronal injury, and dysfunction of surviving neurons [33].

\section{Secondary mechanisms}

Within minutes to days after the primary insult, a myriad of secondary pathological pathways begins. These 
include neuroinflammation, excitotoxicity, oxidative stress, apoptotic cell death, and further BBB disruption, among others $[12,31,33,39,40]$. One of the most common and influential processes to occur is neuroinflammation [12, 41].

Damaged and dying cells release cellular debris including alarmins such as ATP, ROS, and high-mobility group box 1 (HMGB1) [12]. Alarmins are recognized by pattern recognition receptors (PRRs) on glial and immune cells, including toll-like receptors (TLRs) and purinergic receptors [42]. For example, microglia, which act as the primary resident immune cells in the central nervous system (CNS), have been demonstrated to be activated via TLRs (e.g., TLR4) in Sprague-Dawley rats following fluid percussion injury [43]. Microglial activation leads to expression of myeloid differentiation primary response protein 88 (MyD88), nuclear factor $\mathrm{k}$-light-chainenhancer of activated B cells (NF-kB) activation, and downstream cascades of immune signaling $[44,45]$. This includes release of pro-inflammatory cytokines and chemokines such as interleukin (IL)-1 $\beta$, IL-6, IL-12, tumor necrosis factor- $\alpha$ (TNF $\alpha), C C$ chemokine ligand (CCL)2, CXC chemokine ligand (CXCL) 8 and CXCL9, as well as release of oxidative metabolites including nitric oxide (NO) and ROS [12, 46, 47]. Moreover, both alarmins and $\mathrm{NF}-\mathrm{KB}$ activation have been shown to lead to increased expression of the nucleotide-binding oligomerization domain-like receptor family pyrin domain-containing 3 (NLRP3) inflammasome in rodents, causing secretion of the pro-inflammatory cytokines IL-1 $\beta$ and IL-18 $[48,49]$. As the released inflammatory mediators bind receptors on 'surveillant' microglia and trigger their activation, a selfpropagating cycle begins, leading to tissue damage, neurotoxic effects, and dysregulated microglial activation [46, 50-52]. Furthermore, both experimental and clinical studies have demonstrated that microglia activation can persist for months to years depending on the severity and recurrence of TBI, meaning that tissue repair can be chronically hindered [53-58]. It should be noted that, depending on phenotype, microglia can also aid in phagocytosis and remyelination, as well as in the release of antiinflammatory mediators such as IL-10, transforming growth factor- $\beta$ and insulin-like growth factor-1; all of which provide benefit following TBI [50,59].

Astrocytes are also important in neuroinflammation. Following TBI, astrocytes respond via reactive astrogliosis, a transformation that includes gene expression changes and cell hypertrophy to establish a glial scar; the latter of which is thought to be beneficial by isolating the damaged tissue and preventing further cell loss [60, 61]. Similar to microglia, PRRs on astrocytes can be activated by alarmins such as HMGB1 [62]. For example, activation of TLR4 can signal MyD88-dependent and -independent pathways, and NF-kB activation [63].
Downstream release of IL-1 $\beta$, IL-6, TNF- $\alpha$, CCL5, CXCL1, CXCL2, CXCL10, granulocyte-macrophage colony-stimulating factor (GM-CSF), and NO may henceforth occur as demonstrated by both preclinical and clinical studies [60, 64-66]. These inflammatory mediators coupled with those released by microglia, such as IL-1 $\beta$, stimulate further cytokine secretion through NF$\mathrm{\kappa B}$-dependent mechanisms, and may therefore play a role in excitotoxicity [67]. However, the level of reactive astrogliosis is heterogenous and depends on the nature and severity of the TBI [68].

Pro-inflammatory mediators can contribute to BBB permeability and breakdown, and facilitate the infiltration of peripheral immune cells $[31,69,70]$. For example, IL-1 $\beta$, CXCL8 and CCL2 are key mediators in neutrophil and monocyte/macrophage migration into the injured brain parenchyma [71]. As such, it has been demonstrated with a controlled cortical impact (CCI) that within $24 \mathrm{~h}$ of the primary injury, levels of circulating neutrophils increase, and these cells are the first wave of peripheral immune cells to be found within the injury site [72]. Once in the brain parenchyma, neutrophils can become activated by inflammatory mediators and chemokines such as IL-1 $\beta$, TNF $\alpha$, CXCL1, CXCL2, and CXCL8 [73]. Alternatively, neutrophils may interact and become activated via cellcell contact with astrocytes, leading to increased expression of IL-1 $\beta$, IL-6, TNF $\alpha$, and CXCL2 [74]. Neutrophils additionally release ROS which contributes to secondary injury $[75,76]$, and can reciprocally activate microglia, causing a synergistic activation cascade [73]. After this initial wave, murine studies have shown that macrophages become the predominant infiltrating leukocyte and contribute to the production of inflammatory cytokines such as TNF $\alpha$ upon activation [77-79]. Macrophages and other monocytes do, however, also have beneficial neurological properties, such as removal of debris through phagocytosis and assisting remyelination [59].

$\mathrm{T}$ cell infiltration into the injury site is facilitated by $\mathrm{BBB}$ disruption and regulatory $\mathrm{T}$ cell depletion [79-81]. Once at the injury site, $\mathrm{T}$ cells have been shown to become activated to produce T-helper 1 cytokines, such as TNF $\alpha$ and IFN $\gamma$, in mice following CCI [82]. Furthermore, the release of IFNY signals the upregulation of major histocompatibility complex class II protein in microglia (priming the microglia), the release of chemokines and oxidative metabolites, and the further release of pro-inflammatory cytokines [83-85]. However, it has been demonstrated that $\mathrm{T}$ lymphopenia occurs after $\mathrm{CCI}$ in $\mathrm{C} 57 \mathrm{BL} / 6$ mice, potentially as a result of injury-related thymic atrophy and deficits in $\mathrm{T}$ cell maturation [79]. These changes may be coupled with alterations in other immune cell functions as well as lymphoid organs, thereby characterizing peripheral immunosuppression in the acute, sub-acute and even chronic stages post-injury $[79,86]$. 


\section{Functional consequences of TBI}

Following a TBI, cognitive, motor, and emotional abnormalities have been demonstrated in both human and murine studies; however, depending on the nature of the TBI, these consequences may be transient or longlasting [87-91]. Neuroinflammation likely contributes to these deficits, although more research is required to determine the precise mechanisms [92-94]. For example, NLRP3 inflammasome activation has been associated with poor spatial memory in rodents, and elevated serum levels of IL-1 $\beta$ and IL-18 are correlated with increased cognitive impairment in humans $[48,95,96]$. TBI and the later development of neurofibrillary tangles and amyloid- $\beta$ plaque deposition has also been implicated in the presentation of cognitive deficits in both pre-clinical and clinical studies [97-100]. The mechanisms underlying these cognitive impairments are not fully understood; however, synaptic dysfunction as a result of the amyloid- $\beta$ and tau may be a mechanistic link [101]. Post-injury neuroinflammation has also been linked to motor deficits through association with peripheral cell recruitment including $\mathrm{T}$ cell infiltration and microglia activation in murine models [80, 102]. In addition, prolonged anxiety-like behavior as a result of TBI has been reported in both rodents and humans [93, 103-105]. Moreover, increases in anxiety-like behavior have been associated with imbalances of gamma-amino butyric acid (GABA) and a loss of GABAergic interneurons in the basolateral amygdala [106].

PTE is linked to neuroinflammation and evidence suggests it may be the underlying mechanism of seizures and epilepsy development [20, 107]. For example, murine studies have demonstrated that IL-6, TNF $\alpha$, and HMGB1 have pro-ictogenic effects, and potentially act through glutamatergic pathways to promote neuronal hyperexcitability [107-111]. In addition, Il-1 $\beta$ may modulate neuronal hyperexcitability through calcium, glutamatergic, and GABAergic pathways, and the effect of IL-1 $\beta$ on BBB breakdown and neutrophil recruitment may promote epileptogenesis $[112,113]$. TLR4 may also play a role in seizure development as TLR4 mutant mice have demonstrated seizure resistance [111].

\section{Toxoplasma gondii}

\section{Clinical problem of $T$. gondii}

Given that the immune system has evolved to combat pathogens, it is unsurprising that infection, especially in neuronal tissue, could affect TBI outcomes. The direct interaction between infection and TBI would most likely occur in response to common human infections that act chronically and have a tropism for brain tissue. T. gondii is the perfect pathogen in this regard. First discovered in 1908, T. gondii is a globally distributed single-celled intracellular parasite that can infect most vertebrates, including humans [114]. Infection often occurs via contaminated food and water, first leading to an acute infection that spreads around the body [11]. T. gondii then differentiates into a slow growing encysting stage that cannot be cleared by the immune system and resides in a latent form in muscle and the CNS [11]. Prevalence of $T$. gondii infection (based on immunoglobulin G antibodies) considerably varies between age groups and geographical regions $[115,116]$. Children often present with lower rates of infection; however, estimates of seroprevalence in adults range between 5 and 25\% in North America, Western Europe, and East Asia, and upwards of 20\% elsewhere [115-126]. Moreover, countries such as Brazil and Indonesia typically reported adult seroprevalence above $60 \%[115,124,127]$. Historically, $T$. gondii infections have been of great focus in pregnant and immunocompromised populations due to the risk of congenital toxoplasmosis and toxoplasmic encephalitis, respectively [114]. Congenital toxoplasmosis occurs secondarily to maternal infection during or just prior to pregnancy, and can result in a stillborn child, miscarriage, or potential visual or cognitive impairments for the child [128]. Furthermore, in immunocompromised individuals, toxoplasmic encephalitis can result from a lack of lymphocyte recruitment to be able to control parasite replication [129]. This condition is characterized by severe neurological symptoms including seizures, edema, and necrosis of brain tissue [130-132]. In immunocompetent individuals, the infection is typically latent and presents asymptomatically [114]. However, it should be noted that, although immunocompetent individuals appear asymptomatic, chronic infection has been associated with subtle cognitive and behavioral changes [133]. These observations have therefore led to a growing field of research in recent years investigating the potential relationship between $T$. gondii infection and neurological disorders [134, 135].

To date, no cure exists for T. gondii infections [136, 137]. This reflects not only the ability of $T$. gondii to evade the immune system and establish a latent infection but also the heterogeneity of $T$. gondii strains in the clinical population [138]. Strains noticeably differ in virulence, clinical outcomes, and prevalence between regions $[139,140]$. In North America and Europe, approximately $90 \%$ of reported samples can be classified into one of three intercontinental clonal lineages (types I, II, and III) which exhibit approximately $1-2 \%$ differences at the nucleotide level $[141,142]$. Although these lineages are prevalent worldwide [142-144], regional clonal lineages such as Africa 1 and Chinese 1 are also common in Africa and Asia, respectively $[145,146]$. Moreover, a great deal of diversity has arisen in South America as a result of atypical and recombinant strains, and as such clonal lineage prevalence is low [140]. In humans, type II 
strains (e.g., typified by the isolates Prugniaud and ME49) are strongly associated with infection irrespective of clinical presentation; however, differences in virulence have been suggested due to associations of type I and type III strains with cerebral and pulmonary toxoplasmosis, respectively [139]. The vast diversity between strains exemplifies the need to study $T$. gondii virulence effectors, how clinical outcomes vary between strains, and increase awareness of prevention strategies in regions with high $T$. gondii seroprevalence.

\section{T. gondii pathophysiology}

\section{Acute stage}

T. gondii is an obligate intracellular parasite, meaning that it must invade host cells to survive and proliferate [11]. To move through tissue, T. gondii uses a unique form of cellular locomotion called 'gliding motility,' where it then recognizes cognate host cells and initiates a molecular program to invade [147]. Upon invasion, $T$. gondii creates a vacuole around itself (i.e., a parasitophorous vacuole), thereby separating itself from the host cell cytoplasm [147]. T. gondii has a complex life cycle whereby sexual reproduction can only take place in Felidae family members such as domestic cats (Fig. 1) [11]. From Felidae members, encysted forms of the parasite known as oocysts are shed in fecal matter and can persist in soil for more than a year [11, 148]. Furthermore, oocysts are infectious to a wide variety of vertebrates, including humans, and are transmitted when consuming contaminated food and water sources [11, 114]. Upon ingestion, oocysts release sporozoite forms which infect intestinal tissue, differentiate into acute tachyzoite forms,

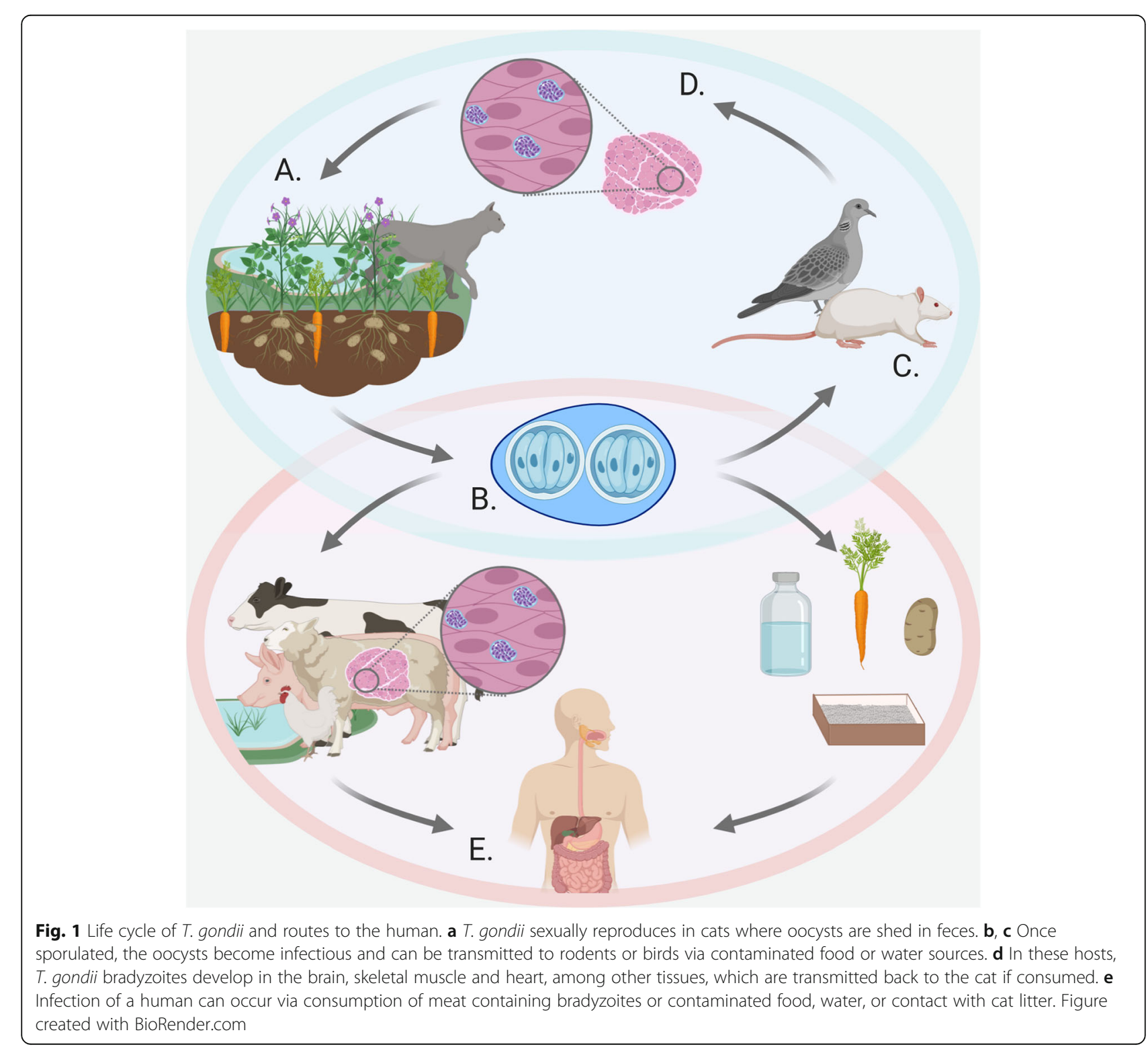


and then spread throughout the body [11].. T. gondii can therefore continue a pattern of invasion, replication and egress within a range of cells, causing tissue damage and toxoplasmosis [147]. Clinical symptoms of acute infection often present as mild flu-like symptoms in people with mature and healthy immune systems, but always result in a chronic infection [149]. The beginning of this chronic stage is characterized by the differentiation of tachyzoites into slower growing bradyzoite forms which develop a glycoprotein-rich wall around the vacuole boundary while living within cells of muscles, organs, and the CNS [150]. Infected vertebrates (e.g., rodents and birds) may therefore contribute to the transmission back to Felidae members; however, incidental infection, such as in humans and livestock, commonly occurs.

$T$. gondii is a highly successful parasite due to its ability to manipulate host cells, skew the immune system, suppress clearance, and even cause the hypermigration of monocytes which can permit cellular dissemination from the site of infection to the whole body [151-155]. $T$. gondii does this by secreting parasite proteins into the host cell cytoplasm and nucleus, which interfere with several cellular pathways [156-160]. Despite the efforts of the immune system to defend the host, T. gondii migrates to the relatively immune-privileged CNS. To achieve this, it has been proposed that $T$. gondii crosses the BBB via one, or a combination of, three mechanisms; hijacking monocytes in a Trojan horse-like manner, transcellular migration, and paracellular migration [161164]. Once in the brain parenchyma, murine models have revealed that several TLRs recognize $T$. gondii [165]. TLR2 and TLR4 have been linked to glycosylphosphatidylinositol detection and TLR2 in particular is considered essential for host resistance [166, 167]. Moreover, some evidence suggests that TLR2 regulates TNF $\alpha$ and CCL 2 production by macrophages and neutrophils, respectively $[167,168]$. TLR11 is a key $T$. gondii sensor in rodents, and is able to recognize $T$. gondii profilin-like protein within endolysosomes, thereby leading to the recruitment of MyD88 and downstream initiation of immune signaling cascades $[44,169,170]$. However, it is important to note that TLR11 is a non-functional gene in humans, and as such the mechanisms of $T$. gondii detection by the human immune system are not fully understood [165]. Nonetheless, in murine models, MyD88 recruitment has been demonstrated to permit production of IL-12 which aids host defence [171]. IL-12 is predominantly produced by non-infected dendritic cells (DCs) during T. gondii infection [172], thereby promoting $\mathrm{T}$-helper 1 responses and subsequent upregulation of IL-2, IL-10, TNF $\alpha$, and IFN $\gamma$ [173].

IFNY is a major effector molecule that acts as a key regulator in host resistance against $T$. gondii, and to date, at least three IFN $\gamma$-mediated protective mechanisms have been identified $[165,174]$. IFN $\gamma$ enhances the ability of human macrophages to kill $T$. gondii [175]. IFNY also suppresses the growth of $T$. gondii via degradation of tryptophan, through activation of indoleamine 2,3-dioxygenase which converts tryptophan into $\mathrm{N}$-formylkyurenine $[176,177]$. As T. gondii is a tryptophan auxotroph, cell starvation occurs. IFN $\gamma$ also leads to free radical production and oxidative stress as a result [165].

The invasion of $T$. gondii in the brain additionally leads to rapid expression of chemoattractants such as CCL5, CXCL9, and CXCL10, by astrocytes and microglia [178]. These chemoattractants recruit $\mathrm{CD}^{+}$and $\mathrm{CD}^{+}{ }^{+} \mathrm{T}$ cells that produce IFNY $[179,180]$. Astrocytic expression of IL$1 \beta$, IL-6, TNF $\alpha$, and GM-CSF is also increased upon $T$. gondii infection of the CNS [181]. Upregulation of numerous other inflammatory cytokines including IL-2, IL-4, IL10 , and IL-12 have been noted through rodent studies in the CNS during acute T. gondii infection [182].

\section{Chronic stage}

Once in the CNS, tachyzoites differentiate into encysted bradyzoites which are resistant to immune clearance, resulting in life-long chronic infection [183]. These cysts are predominantly found intracellularly in the grey matter, with $T$. gondii residing in cell processes $[184,185]$. Like in tachyzoite stages, it is highly likely that bradyzoites also manipulate their host cell, although this is far less well understood [186, 187]. One remarkable aspect during infection of the brain is that $T$. gondii seems to also 'inject' parasite proteins into neurons that it does not infect [184, 185]. While it is not understood what role this has during infection, one possible result of this could be a more widespread immunological modulation of tissue, which could have significant consequences.

In the chronic stage of $T$. gondii infection, it has been demonstrated that microglia populations remain in a more 'pro-inflammatory' state [188]. This is coupled with levels of numerous inflammatory mediators, such as IL-6, TNF $\alpha$, IFN $\gamma$, and GM-CSF remaining above control levels despite showing a decrease from the acute stage [188]. Furthermore, markers of $\mathrm{T}$ cell differentiation and exhaustion are simultaneously expressed, which indicates that IFN $\gamma$-mediated inflammatory responses are chronically limited to potentially assist parasite survival [188].

In addition to an inflammatory response, $T$. gondii infection causes several neurochemical changes including glutamate and dopamine dysregulation $[189,190]$. During chronic infection with $T$. gondii, the astrocytic glutamate transporter GLT-1 is reportedly reduced in the forebrain over time, leading to increases in extracellular glutamate and excitotoxicity [189]. Interestingly, the $T$. gondii genome contains aromatic amino acid 
hydroxylase (AAH) genes (AAH1 and AAH2) that encode the levodopa protein (precursor to dopamine), suggesting direct modulation by the parasite [191]. However, the impact of $T$. gondii on global dopamine levels remains controversial, with both increases and decreases reported [192-196].

Ultimately, $T$. gondii infection leads to alterations in brain structure and function [197]. Of importance, somatosensory regions have been noted to contain lesions, and loss of fiber coherence and density [198]. Reductions in dendritic complexity and length have also been observed, as well as a loss of synaptic complexity [189, 196, 198]. Chronic T. gondii infection has further been linked to microcirculatory dysfunction and reduced angiogenesis in the brain [199], which may contribute to neurodegenerative processes.

\section{Functional consequences of $T$. gondii infection}

As it has been shown and now well accepted that T. gondii influences the mammalian brain and is associated with some brain disorders [134], to appreciate whether T. gondii could contribute to TBI, it is important that we review what is already known about the effect this parasite has on the brain. In 1979, it was discovered that T. gondii infection in rodents caused changes in learning [134]. Since then, murine models have provided insight into the multitude of behavioral alterations that may occur in response to this infection [200]. These include changes in memory and learning, locomotion, anxiety, depression-like behaviors, social behavior, and predator aversion [134]. However, in humans, studies into T. gondii infection-based changes are limited to epidemiological and serological studies, and as such, are primarily retrospective and associative [135, 201].

Memory and learning changes have received little attention in the literature compared to other behavioral modalities, and the murine studies that have been conducted report inconsistent results [202, 203]. These inconsistencies may be attributed to differences in parasite strain, cyst burden, behavioral paradigm, rodent species, sex, and post-infection time of testing [204-207]. For example, it has been demonstrated that female BALB/c mice infected with the ME49 strain of T. gondii, but not the Prugniaud strain, exhibit impaired spatial working memory at 2 months post-infection [205]. Overall though, the limited literature points toward spatial learning, working memory, and short-term memory being impaired in murine models due to T. gondii infection [203-205, 208].

Similarly, there is mixed literature regarding changes in anxiety and depression associated with $T$. gondii infection and controversy exists as a result. Overall, most published literature indicates that $T$. gondii infected rodents have increased anxiety in both the acute and chronic stages of infection [209-212]. One study, however, found that infected rats displayed decreased anxiety [213]. Associative clinical studies have linked $T$. gondii infection to depression [214, 215]; however, only some studies have shown $T$. gondii infection to induce depression-like behavior in rodents [210, 216]. Moreover, Bay-Richter and Petersen [212] suggest that depressive-like behavior is only affected in genetically vulnerable $T$. gondii rodents. Taken together, postinfection time of testing and gene-environment interactions are important factors that influence the response to infection, and these should be considered in study design and analysis [212].

Social behavior and the link between $T$. gondii and neuropsychiatric disorders have been of great interest over the last several years. In particular, the association between chronic $T$. gondii infection and schizophrenia has been growing in the literature $[217,218]$. Sociability with novel mice is impaired in mice chronically infected with $T$. gondii, which may reflect this potential link between T. gondii and schizophrenia [211].

There is also mixed evidence suggesting an association between chronic $T$. gondii infection and neurological conditions such as epilepsy and AD. A previous comprehensive systems analysis found that $T$. gondii infection modified pathways involved in epilepsy and neurodegenerative diseases [219], and a recent meta-analysis concluded that $T$. gondii infection is a risk factor for AD [220]. There is also preclinical evidence suggesting that T. gondii infection promotes the development of epilepsy and $\mathrm{AD}$ in rodents [208, 221, 222]. On the other hand, a case-controlled study involving 99 epilepsy patients and 99 patients without epilepsy found no association between $T$. gondii infection and epilepsy [223]. It has been noted that both hyperphosphorylated tau as well as amyloid- $\beta$ plaques (i.e., pathologies implicated in epilepsy and $\mathrm{AD}$ [224]) can be induced in murine models following chronic $T$. gondii infection [221]. In contrast, phagocytosis of amyloid- $\beta$ has also been demonstrated to be enhanced in chronic T. gondii infection, indicating a modulatory role of recruited immune cells [225]. These differing conclusions may again be due to differences in the murine models and human studies, as well as the post-infection time of analysis. However, these conflicting results highlight the need to expand the field of $T$. gondii research, as well as implement multiple models or endpoints into study designs.

\section{The pathophysiological links between TBI and $T$. gondii}

Given the overlapping neuroinflammatory processes of TBI and T. gondii and the known effects that chronic infection can have on the function of the brain (Fig. 2), it is possible that an individual who sustains a TBI while chronically infected with $T$. gondii will present with 


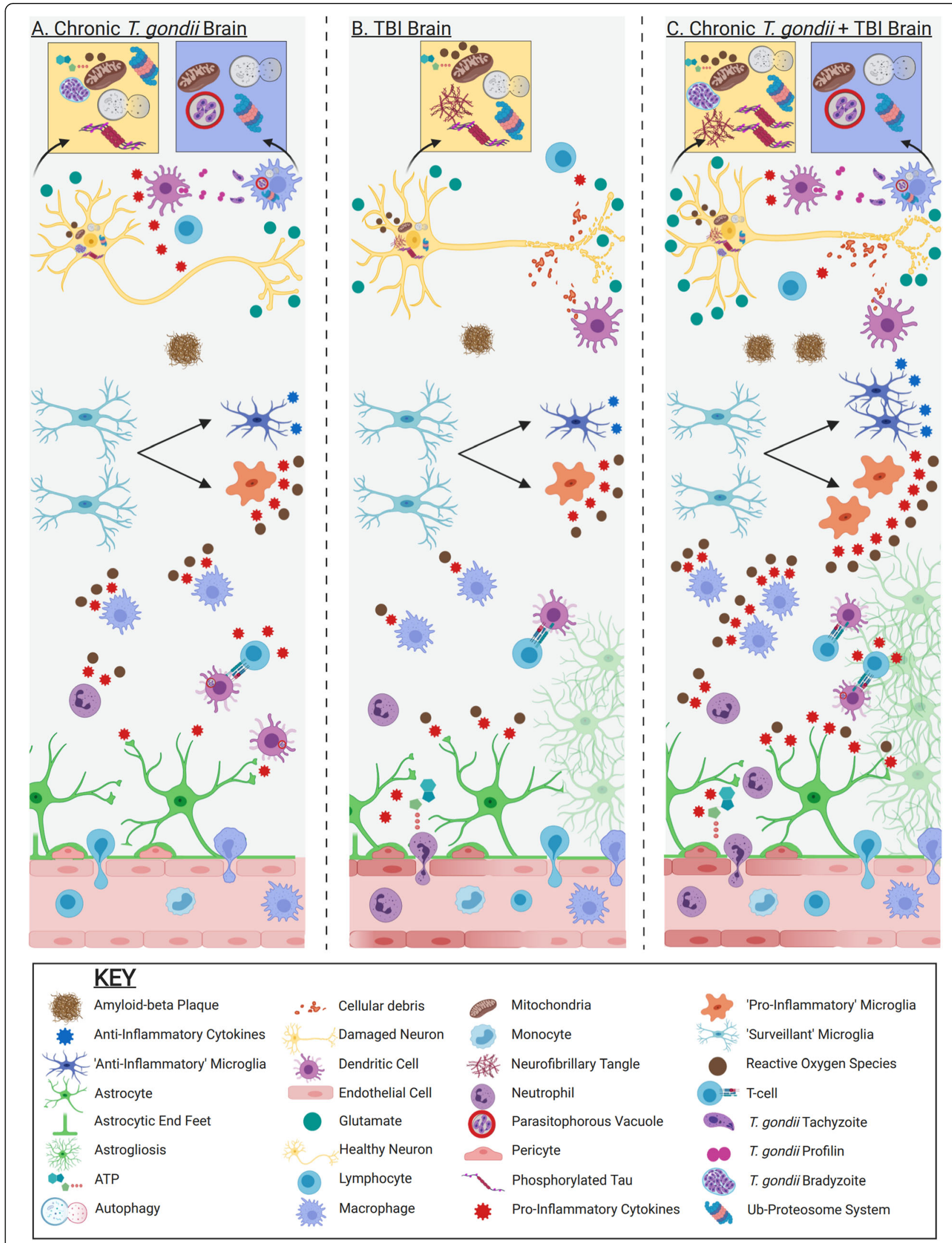

Fig. 2 (See legend on next page.) 
(See figure on previous page.)

Fig. 2 Neuroimmunological processes of chronic T. gondii infection and TBI, including the hypothesized synergy between conditions. a Chronic T. gondii brain. After migration into brain parenchyma, T. gondii profilin is detected by non-infected dendritic cells. This leads to production of IL-12 which activates lymphocytes to secrete IFNy mediating host resistance. Infected and IFNy-primed dendritic cells prime T cells and trigger production of IFNy. IFNy then activates astrocytes, leading to secretion of pro-inflammatory cytokines such as IL-1 $\beta$, IL-6, and GM-CSF. GM-CSF can prime microglia, leading to the production of TNF-a, IL-6, and ROS. IFNy and TNFa further activate macrophages, leading to secretion of proinflammatory cytokines and ROS, thereby further inhibiting T. gondii replication in macrophages. However, T. gondii preferentially infects neurons, and once inside, bradyzoites develop to avoid clearance. b TBI. Immediately following injury, damaged pericytes and parenchyma release alarmins such as ATP and ROS. These signaling molecules activate microglia and astrocytes to promote release of inflammatory cytokines and ROS. Leukocyte recruitment to the injury site begins with neutrophil infiltration, followed by macrophages and T cells. In response to cellular debris, T cells and macrophages produce additional pro-inflammatory cytokines. c Chronic T. gondii + TBI Brain. If an individual harboring a chronic T. gondii infection were to sustain a TBI, the neuroinflammatory profile may be exacerbated. A greater population of 'pro-inflammatory' and 'anti-inflammatory' microglia, as well as activated astrocytes, may be present not only at the onset of injury but also post-TBI. Increased populations of these cells may result in an increase of the relative abundance of inflammatory mediators post-TBI. Increased numbers of activated neutrophils, T cell, and macrophages may additionally be present, with the potential for these cells to further produce inflammatory mediators. Additionally, hyperphosphorylated tau and amyloid- $\beta$ may accumulate more readily, potentially accelerating the neurodegenerative process. Figure created with BioRender.com

exacerbated neuroinflammation. Also, the large indiscriminate release of glutamate after TBI, coupled with the increased extracellular glutamate in chronic T. gondii infection, could result in further excitotoxicity and downstream inflammation and phosphorylation of tau [189, 226, 227].

Subclinical neuroinflammation that occurs in a chronic T. gondii infection could be exacerbated by a TBI due to an increased population of activated microglia and astrocytes. Similar to increases in astrogliosis and activated microglial populations following repeated mild TBIs [228], it is possible a TBI sustained during a chronic T. gondii infection may act as a 'second hit' given that $T$. gondii can elicit a 'pro-inflammatory' microglial population [188]. In other words, after the insult, primed microglia could excessively produce proinflammatory cytokines such as IL-1 $\beta$, IL-6, IL-12, TNF $\alpha$, and IFN $\gamma$ [229], and additional 'surveillant' microglia and astrocytes may become activated to produce additional inflammatory mediators. These cascades would result in a greater proportion of astrogliosis and activated microglia compared to TBI individuals without T. gondii. Moreover, the proposed excessive inflammatory mediators secreted acutely after TBI may activate the sympathetic nervous system (SNS) and hypothalamic-pituitary-adrenal (HPA) axis, resulting in an exacerbated systemic inflammatory response [230, 231]. Negative feedback via the SNS and HPA axis could therefore be triggered, leading to increased peripheral immune cell and lymphoid organ dysfunction, and more pronounced immunosuppression compared to TBI individuals without infection [232]. As immunosuppression can result from TBI [79], it is also plausible that individuals may exhibit symptoms of toxoplasmic encephalitis given that control of chronic $T$. gondii infection requires continual immune cell infiltration [129, 233]. In other words, individuals may be vulnerable to tachyzoite proliferation and subsequent increased neuroinflammatory sequelae sub-acutely or chronically post-injury. An individual may, for example, present with increased necrotic cell death and lesional volume due to increased inflammatory-related cell damage. This could have further long-term consequences of exacerbated functional deficits.

With regards to glutamate and excitotoxicity, murine studies have also suggested a $T$. gondii-induced reduction of astrocytic GLT-1, which is likely to exacerbate TBI-induced excitotoxic effects if a chronic infection were to precede a TBI $[33,189]$. This could further dysregulate GLT-1 post-TBI, thereby contributing to increased excitotoxicity and neuronal damage or death [234]. The temporal profile of elevated glutamate may additionally be altered if the insults occur together, given that in humans, severe TBI alone can result in elevated glutamate that can persist for days or weeks in some brain structures $[235,236]$.

The changes to the brain's structure and function, including alterations to dendrites, synapses, and microvasculature as a result of chronic T. gondii [197], together with the widespread injury to axons, neurons, and cerebrovasculature induced by the mechanical insult of the TBI may cause an increased lesion volume if the conditions occur concurrently [237]. The increased level of ROS, NO, and oxidative stress as a result of TBI, compounded with increased $\mathrm{NO}$ in chronic T. gondii infection, may additionally trigger profuse neuronal death $[238,239]$. As ROS facilitates BBB permeability and breakdown $[69,240]$, excessive ROS in combination with increased pro-inflammatory cytokines could escalate BBB breakdown and peripheral cell recruitment, dysregulate ionic flux across the barrier, and increase lesion volume [240, 241]. Furthermore, as amyloid- $\beta$ accumulation and hyperphosphorylated tau have been implicated in both $T$. gondii and TBI separately [221, 242], when the conditions occur simultaneously, an amplification of these products could occur, further exacerbating oxidative stress and associated damage, and accelerating neurodegenerative changes [243, 244]. 
In terms of behavioral outcomes, as mentioned previously, $T$. gondii infection alone has been shown to induce subtle deficits in cognitive functioning, motor functioning, and social behavior [134, 211]. Adding to this, T. gondii infection has been associated with increased anxiety and depression [211, 212]. Coupled with a TBI, which is causal to similar impairments, an exacerbation of deficits in functional outcomes could occur. For example, given the links between $T$. gondii and TBI with epilepsy [20,245], it is possible that epileptogenesis could occur more readily as a result of exacerbated IL$1 \beta$ production, glutamatergic and GABAergic pathways. Moreover, T. gondii infection could lead to temporal changes in deficits that occur with TBI, such that deficits occur over a long-term scale rather than transiently. This would mean worse functional outcomes after TBI in individuals chronically infected with $T$. gondii compared to those without infection, and supplementary rehabilitation may be necessary. Additionally, the possible cumulative effect may result in lifelong functional deficits as a result of increased structural damage. Together, $T$. gondii and TBI may also accelerate neurodegeneration given that both are independently implicated in the production of neuroinflammation, hyperphosphorylated tau and amyloid- $\beta$ plaques, as well as alterations to glutamatergic and GABAergic pathways [106, 189, 221, 242]. Therefore, individuals may be at an increased risk of developing chronic neurological conditions such as PTE and $\mathrm{AD}$, among others [20, 23, 208].

The potential for synergism between $T$. gondii and TBI is further complicated by factors such as biological sex and age, as both are known to modify neuroinflammatory and recovery pathways. For example, murine studies have demonstrated a divergent response up to 7 days post-injury, with more robust microglial activation, astrogliosis, and cell loss in young adult males compared to young adult females after a moderate to severe CCI [246, 247]. Therefore, when coupled with a chronic $T$. gondii infection, young adult males that have sustained a TBI may have worse outcomes compared to their female counterparts. Though, it should be noted that although preclinical studies often report better outcomes in females, the findings are mixed in human studies [248, 249]. Regarding the impact of age, preclinical studies show that aged rodents have exacerbated microglial activation and pro-inflammatory cytokines coupled with increased functional deficits post-injury compared to young-adult rodents [250252]. Given that $T$. gondii seroprevalence increases with age, elderly individuals may be at an increased risk of experiencing the two conditions concurrently and may experience worse outcomes post-injury compared to younger TBI individuals with chronic $T$. gondii infection [120].

\section{Future directions}

This review has highlighted numerous areas of pathological overlap between T. gondii and TBI, which in theory could exacerbate the functional consequences of these conditions. With that said, to the best of our knowledge, no literature examining the overlap between T. gondii and TBI exists, and a great deal of future research is still required. First and foremost, studies must be done to comprehensively characterize if and how $T$. gondii infection modifies the aftermath of TBI. Animal models will be invaluable to assist in characterizing the hypothesized synergism between T. gondii and TBI, and validated rodent models of TBI and $T$. gondii infection exist already [4, 134, 253]. Animal models additionally allow for highly controlled study designs to assist initial delineation of mechanisms for a given sex or age. Large studies of clinical TBI populations should also be conducted in parallel to complement preclinical data. For example, T. gondii infection could be screened when TBI patients present to Emergency Departments, thus allowing for analyses of pathophysiological and outcome differences between TBI patients with and without $T$. gondii. Indeed, it is still not known how many latent $T$. gondii parasites are found in any tissue type in human let alone the brain. Current tests can only determine exposure by immunoglobulin $\mathrm{G}$ antibody response and are not informative about where latent forms reside in the human body. This is an important consideration and something that needs to be determined as we would only expect synergy of $T$. gondii and TBI if there were sufficient levels of parasites in the brain to exacerbate inflammation. Taken together, these studies are imperative in our understanding of how TBI and T. gondii interact, and provide a foundation to develop and optimize appropriate treatments for TBI patients with and without $T$. gondii to improve outcomes.

There are several existing drug candidates that could target overlapping mechanisms in T. gondii and TBI to minimize secondary injury. For example, the NLRP3 inhibitor MCC950, which has been demonstrated in several preclinical TBI studies to decrease neuroinflammation and improve cognitive and motor deficits, may prove efficacious when the conditions appear concomitantly [48, 49, 254]. MCC950 has additionally been demonstrated to decrease IL-1 $\beta$ secretion upon monocyte infection with $T$. gondii [255]; however, there is an absence of research pertaining to this inhibitor in in vivo chronic infection models. The IL-1 receptor antagonist, Anakinra, is another potential drug intervention in this context, and has already demonstrated safety and tolerability in human TBI trials [256]. Experimental studies have reported that Anakinra is beneficial in mice with a combined TBI and tibial fracture [257]. This injury combination results in exacerbated neuroinflammation compared to an isolated TBI 
[258], and may bear similarities to what would occur in a combined TBI and T. gondii setting.

The $\alpha 2$-adrenergic agonist Guanabenz may be another suitable drug candidate in the context of TBI combined with $T$. gondii, given its ability to downregulate inflammatory responses via elevation of eukaryotic initiation factor 2 alpha subunit (eIF2 $\alpha$ ) phosphorylation [259, 260]. Moreover, Guanabenz has been shown to be effective in reducing inflammation and cyst burden during the chronic stage of $T$. gondii $[259,261]$, as well as reduce endoplasmic reticulum (ER) stress and hence reduce neuronal loss post-TBI [262, 263]. Guanabenz may also be beneficial by decreasing sympathetic hyperactivity [264]. The eIF $2 \alpha$ dephosphorylation inhibitor, Salubrinal, has additionally shown benefit in both $T$. gondii and TBI studies independently $[265,266]$. In chronic T. gondii infection, Salubrinal has been demonstrated to inhibit the reactivation of bradyzoites [265]; and through TBI studies, it was established to suppress ER stress, as well as autophagy and apoptosis pathways, thereby reducing morphological and functional deficits post-injury [266]. Though Salubrinal does not target the overlapping neuroinflammatory pathways directly, it may still prove beneficial in reducing cell death acutely after injury, and bradyzoite reactivation if immunosuppression were to occur.

However, it is important to consider the possibility that these treatments may prove detrimental in those with a $T$. gondii infection, given that certain inflammatory processes are also necessary to control parasite replication. In other words, if an individual with a chronic $T$. gondii infection were to receive a neuroinflammatorybased drug candidate post-TBI, T. gondii tachyzoite replication may reactivate, resulting in uncontrollable parasite proliferation, exacerbated cell death, and clinical symptoms of toxoplasmosis. This therefore would have the opposite effect to what was intended. Hence, it would be beneficial to additionally investigate neuroinflammatory drug candidates with standard treatment strategies for reactivated toxoplasmosis, such as pyrimethamine-sulfadiazine therapy [267]. This particularly highlights the importance of future research investigating TBI coupled with T. gondii infection, in both the preclinical and clinical setting.

It would also be of interest to examine the incidence of TBI in individuals both with and without a preexisting $T$. gondii infection. With growing evidence that $T$. gondii infection in and of itself may result in subtle behavioral abnormalities, it could be the case that these behaviors result in either increased or decreased risk of sustaining a future TBI. For example, T. gondii infection has been demonstrated to increase the risk of having a traffic accident [268]. As motor accidents are a common cause of TBI, these adults may consequently be at a higher risk of sustaining a TBI [18]. T. gondii seropositivity has also been associated with increased aggression and impulsivity in healthy adults [269]. These adults may engage in more risk-taking behavior than $T$. gondii seronegative individuals and additionally be at an increased risk of sustaining a TBI. Furthermore, this would align with a previous study demonstrating individuals with intermittent explosive disorder (which is characterized by impulsive aggression) were more likely to have a history of mild TBI [270].

As T. gondii seroprevalence increases with age, and those above 75 years of age account for a significant proportion of TBI-related hospitalizations and deaths, it would also be important to consider the incidence of TBI individuals with or without infection for this age group [120, 271]. Importantly, as aging is associated with immune system dysregulation as well as increased levels of basal inflammation, future studies investigating the effect of age on the hypothesized synergism of chronic T. gondii infection with TBI are essential [272].

Although the focus of this paper has been in the context of someone with chronic $T$. gondii experiencing a TBI, it should also be considered that a history of TBI may predispose individuals to worse outcomes upon a later $T$. gondii infection. For example, TBI can increase the proportion of activated microglia and neuroinflammation chronically after post-injury [55]. T. gondii would therefore be met upon migration to the brain parenchyma with a more robust neuroinflammatory response, potentially leading to excessive cell death. Moreover, if immunosuppression were to result from a TBI [79], and an individual were to be later infected with $T$. gondii, uncontrolled proliferation of tachyzoites may occur in enterocytes and once migrated into the brain parenchyma, exacerbated activation of apoptotic pathways may occur due to cell stress via tachyzoite proliferation, and necrotic tissue may result [273].

More broadly, it would also be of significance to determine whether peripheral parasitic infections, such as with enteric parasites, can alter TBI outcomes. Much like with a chronic $T$. gondii infection, a significant proportion of the clinical TBI population would be likely to encounter an intestinal parasite at some point either before or after injury. Amplified microglial activation, proinflammatory mediators, and functional deficits have previously been demonstrated through peripheral lipopolysaccharide challenge post-TBI [6, 274-276]. Additionally, as peripheral immunosuppression and braingut axis dysregulation can eventuate in the aftermath of a TBI, increased susceptibility to peripheral infection and increased mortality rate can occur [274, 276, 277]. Therefore, it is reasonable to predict a similar pattern of exacerbation would occur as a result of peripheral parasitic immunological stressors, among other types of 
peripheral infections. However, to date, this has been an understudied topic, and this field of research requires greater attention in future studies.

By the same token, it is important to consider how other common neurologically involved parasitic infections may alter TBI pathophysiology and outcomes. For example, Plasmodium falciparum has been attributed to upward of half a million deaths annually, and can result in cerebral malaria [278, 279]. Cytoadherence of parasitized erythrocytes to the endothelium can initiate inflammatory pathways and may contribute to $\mathrm{BBB}$ disruption [279]. Therefore, coupled with the BBB alterations that are commonplace post-TBI, an exacerbated proinflammatory response may occur alongside excessive neurovascular damage and increased edema. As cerebral malaria is a risk factor for epilepsy, it would also be of importance to investigate whether a Plasmodium infection paired with a TBI could increase the incidence of PTE [280, 281]. Additionally, members of the Trypanosomatidae family warrant investigation as potential modifiers of TBI outcomes, particularly given that human African trypanosomiasis presents with a late meningoencephalitic stage [282]. African trypanosomes are capable of crossing the BBB into the brain parenchyma and increased expression of pro-inflammatory mediators, such as TNFo, IFN $\gamma$, and CXCL10, is believed to assist parasitic invasion of the CNS [283, 284]. However, the signaling pathways involved have not been extensively studied. As circadian rhythm disturbances are commonly reported post-TBI, another intriguing prospect for interplay between African trypanosomes and TBI would be in regard to circadian rhythm alterations given that African trypanosomes are notoriously known to reverse sleep cycles [282, 285]. Chagas disease, which is also known as American trypanosomiasis, is common in Latin American stroke patients and can present with highly varied neurological manifestations [286, 287]. However, as cardiac and digestive tissues are predominantly infected, with cardiomyopathy being the main clinical feature in the chronic stage, neuroinflammatory events have not been well characterized for this disease and the capacity to speculate about a potential overlap with TBI pathophysiology is limited [288]. Ultimately, the high prevalence and unique neuropathology of a $T$. gondii infection, coupled with the shear lack of etiological knowledge surrounding cerebral complications of malaria and trypanosomiasis, further solidifies T. gondii as the prime candidate to begin investigations between parasitic infection and TBI.

\section{Conclusions}

In closing, TBI is a key contributor to the global burden of disease but despite promising preclinical trials, to date no effective treatments exist. This reflects the heterogeneity of TBI pathophysiology and presentation, such as the presence of infection. T. gondii chronically infects approximately one-third of the world's population, which equates to a significant proportion of individuals who sustain a TBI being chronically infected with $T$. gondii at the time of insult. As there are a myriad of neuroinflammatory processes that are common to both conditions, exacerbated neuroinflammation, amplified functional deficits, and accelerated neurodegenerative processes may occur in TBI individuals who are confirmed with chronic T. gondii infection. The interplay between $T$. gondii and TBI however remains speculative and as such, further investigations should be conducted to assist TBI treatment development and future clinical practice.

\begin{abstract}
Abbreviations
AAH: Aromatic amino acid hydroxylase; AD: Alzheimer's disease; ATP: Adenosine triphosphate; BBB: Blood-brain barrier; CCL: CC chemokine ligand; CNS: Central nervous system; CXCL: CXC chemokine ligand; DC: Dendritic cell; elF2a: Eukaryotic initiation factor 2 alpha subunit; ER: Endoplasmic reticulum; GABA: Gamma-amino butyric acid; GLT: Glutamate; GM-CSF: Granulocyte-macrophage colony-stimulating factor; HMGB1: High-mobility group box 1; HPA: Hypothalamic-pituitary-adrenal; IL: Interleukin; IFNץ: Interferon-ү; MyD88: Myeloid differentiation primary response protein 88; NF-KB: Nuclear factor k-light-chain-enhancer of activated B cells; NLRP3: Nucleotide-binding oligomerization domain-like receptor family pyrin domain-containing 3; NO: Nitric oxide; PRR: Pattern recognition receptor; PTE: Post-traumatic epilepsy; ROS: Reactive oxygen species; SNS: Sympathetic nervous system; TBI: Traumatic brain injury; TLR: Toll-like receptor; TNFa: Tumor necrosis factor-a
\end{abstract}

\section{Acknowledgements \\ TLB is supported by an Australian Government Research Training Program (RTP) Scholarship.}

\section{Authors' contributions}

All authors contributed to the concept of this manuscript. TLB performed literature searching and drafted the manuscript. All authors critically reviewed and edited the content of this manuscript. The author(s) read and approved the final manuscript.

Authors' information

Not applicable.

\section{Funding}

SRS and RM are supported by NHMRC and CIHR funding.

Availability of data and materials

Not applicable.

Ethics approval and consent to participate

Not applicable.

Consent for publication

Not applicable.

\section{Competing interests}

The authors declare that they have no competing interests.

\section{Author details}

'Department of Neuroscience, Monash University, 6th Floor, The Alfred Centre, 99 Commercial Road, Melbourne, VIC 3004, Australia. ${ }^{2}$ Department of Medicine, The University of Melbourne, Parkville, VIC, Australia. ${ }^{3}$ Division of Infectious Diseases and Defence, The Walter and Eliza Hall Institute of Medical Research, Parkville, VIC, Australia. 
Received: 21 April 2020 Accepted: 2 July 2020

\section{Published online: 25 July 2020}

\section{References}

1. Dewitt DS, Hawkins BE, Dixon CE, Kochanek PM, Armstead W, Bass CR, et al. Pre-clinical testing of therapies for traumatic brain injury. J Neurotrauma. 2018:35(23):2737-54

2. GBD 2016 Traumatic Brain Injury and Spinal Cord Injury Collaborators. Global, regional, and national burden of traumatic brain injury and spinal cord injury, 1990-2016: a systematic analysis for the Global Burden of Disease Study 2016. Lancet Neurol. 2019:18(1):56-87.

3. Stein DG. Embracing failure: What the Phase III progesterone studies can teach about TBI clinical trials. Brain Inj. 2015;29(11):1259-72

4. Shultz SR, McDonald SJ, Vonder Haar C, Meconi A, Vink R, van Donkelaar P, et al. The potential for animal models to provide insight into mild traumatic brain injury: Translational challenges and strategies. Neurosci Biobehav Rev. 2017;76:396-414.

5. Sun M, McDonald SJ, Brady RD, O'Brien TJ, Shultz SR. The influence of immunological stressors on traumatic brain injury. Brain Behav Immun. 2018:69:618-28.

6. Collins-Praino LE, Arulsamy A, Katharesan V, Corrigan F. The effect of an acute systemic inflammatory insult on the chronic effects of a single mild traumatic brain injury. Behav Brain Res. 2018;336:22-31.

7. Domowicz M, Wadlington NL, Henry JG, Diaz K, Munoz MJ, Schwartz NB Glial cell responses in a murine multifactorial perinatal brain injury model. Brain Res. 2018:1681:52-63.

8. Leitgeb J, Mauritz W, Brazinova A, Majdan M, Wilbacher I. Impact of concomitant injuries on outcomes after traumatic brain injury. Arch Orthop Trauma Surg. 2013;133(5):659-68.

9. Leong BK, Mazlan M, Abd Rahim RB, Ganesan D. Concomitant injuries and its influence on functional outcome after traumatic brain injury. Disabil Rehabil. 2013;35(18):1546-51.

10. McDonald SJ, Sun M, Agoston DV, Shultz SR. The effect of concomitant peripheral injury on traumatic brain injury pathobiology and outcome. J Neuroinflammation. 2016;13(1):90

11. Montoya JG, Liesenfeld O. Toxoplasmosis. Lancet. 2004;363(9425):1965-76.

12. Jassam YN, Izzy S, Whalen M, McGavern DB, El Khoury J. Neuroimmunology of traumatic brain injury: time for a paradigm shift. Neuron. 2017;95(6): 1246-65.

13. Wang $T$, Sun $X$, Qin $W$, Zhang $X$, Wu L, Li Y, et al. From inflammatory reactions to neurotransmitter changes: implications for understanding the neurobehavioral changes in mice chronically infected with Toxoplasma gondii. Behav Brain Res. 2019:359:737-48.

14. Humphreys I, Wood RL, Phillips CJ, Macey S. The costs of traumatic brain injury: a literature review. Clinicoecon Outcomes Res. 2013;5:281-7.

15. Barker-Collo S, Theadom A, Jones K, Feigin VL, Kahan M. Accuracy of an international classification of diseases code surveillance system in the identification of traumatic brain injury. Neuroepidemiology. 2016;47(1): 46-52.

16. Feigin VL, Theadom A, Barker-Collo S, Starkey NJ, McPherson K, Kahan M, et al. Incidence of traumatic brain injury in New Zealand: a populationbased study. Lancet Neurol. 2013;12(1):53-64.

17. Theadom A, Starkey NJ, Dowell T, Hume PA, Kahan M, McPherson K, et al. Sports-related brain injury in the general population: an epidemiological study. J Sci Med Sport. 2014;17(6):591-6.

18. Brazinova A, Rehorcikova V, Taylor MS, Buckova V, Majdan M, Psota M, et al. Epidemiology of traumatic brain injury in Europe: a living systematic review. J Neurotrauma. 2018.

19. GBD 2016 Neurology Collaborators. Global, regional, and national burden of neurological disorders, 1990-2016: a systematic analysis for the Global Burden of Disease Study 2016. Lancet Neurol. 2019;18(5):459-80.

20. Webster K, Sun M, Crack P, Obrien T, Shultz S, Semple B. Inflammation in epileptogenesis after traumatic brain injury. J Neuroinflammation. 2017; 14(1):10.

21. Bombardier CH, Fann JR, Temkin NR, Esselman PC, Barber J, Dikmen SS. Rates of major depressive disorder and clinical outcomes following traumatic brain injury. JAMA. 2010;303(19):1938-45.

22. Molloy C, Conroy RM, Cotter DR, Cannon M. Is traumatic brain injury a risk factor for schizophrenia? A meta-analysis of case-controlled populationbased studies. Schizophr Bull. 2011;37(6):1104-10.
23. Jellinger KA. Traumatic brain injury as a risk factor for Alzheimer's disease. J Neurol Neurosurg Psychiatry. 2004;75(3):511-2.

24. Gardner RC, Byers AL, Barnes DE, Li Y, Boscardin J, Yaffe K. Mild TBI and risk of Parkinson disease. Neurology. 2018;90(20):e1771-9.

25. Cheng C, Chi NC, Williams E, Thompson HJ. Examining age-related differences in functional domain impairment following traumatic brain injury. Int J Older People Nursing. 2018;13(4):e12208.

26. Mollayeva T, Mollayeva S, Colantonio A. Traumatic brain injury: sex, gender and intersecting vulnerabilities. Nat Rev Neurol. 2018;14(12):711-22.

27. Watanabe T, Kawai Y, Iwamura A, Maegawa N, Fukushima H, Okuchi K. Outcomes after traumatic brain injury with concomitant severe extracranial injuries. Neurol Med Chir (Tokyo). 2018;58(9):393-9.

28. Armistead-Jehle P, Soble JR, Cooper DB, Belanger HG. Unique aspects of Traumatic brain injury in military and veteran populations. Phys Med Rehabil Clin N Am. 2017:28(2):323-37.

29. MCAllister TW. Neurobiological consequences of traumatic brain injury. Dialogues Clin Neurosci. 2011;13(3):287-300.

30. Xiong Y, Mahmood A, Chopp M. Animal models of traumatic brain injury. Nat Rev Neurosci. 2013;14(2):128-42.

31. Shlosberg D, Benifla M, Kaufer D, Friedman A. Blood-brain barrier breakdown as a therapeutic target in traumatic brain injury. Nat Rev Neurol. 2010;6(7):393-403.

32. Wolf JA, Stys PK, Lusardi T, Meaney D, Smith DH. Traumatic axonal injury induces calcium influx modulated by tetrodotoxin-sensitive sodium channels. J Neurosci. 2001;21(6):1923-30.

33. Guerriero R, Giza C, Rotenberg A. Glutamate and GABA imbalance following traumatic brain injury. Curr Neurol Neurosci Rep. 2015;15(5):1-11.

34. Chamoun R, Suki D, Gopinath SP, Goodman JC, Robertson C. Role of extracellular glutamate measured by cerebral microdialysis in severe traumatic brain injury. J Neurosurg. 2010;113(3):564-70.

35. Folkersma H, Foster Dingley JC, van Berckel BNM, Rozemuller A, Boellaard R, Huisman MC, et al. Increased cerebral (R)-[(11)ClPK11195 uptake and glutamate release in a rat model of traumatic brain injury: a longitudinal pilot study. J Neuroinflammation. 2011;8:67.

36. Nilsson P, Hillered L, Pontén U, Ungerstedt U. Changes in cortical extracellular levels of energy-related metabolites and amino acids following concussive brain injury in rats. J Cereb Blood Flow Metab. 1990;10(5):631-7.

37. Dorsett CR, McGuire JL, DePasquale EAK, Gardner AE, Floyd CL, McCullumsmith RE. Glutamate neurotransmission in rodent models of traumatic brain injury. J Neurotrauma. 2017;34(2):263-72.

38. Lin C-LG, Kong Q, Cuny GD, Glicksman MA. Glutamate transporter EAAT2: a new target for the treatment of neurodegenerative diseases. Future Med Chem. 2012;4(13):1689-700.

39. Johnson VE, Stewart W, Smith DH. Axonal pathology in traumatic brain injury. Exp Neurol. 2013;246:35-43.

40. Minambres E, Ballesteros MA, Mayorga M, Marin MJ, Munoz P, Figols J, et al. Cerebral apoptosis in severe traumatic brain injury patients: an in vitro, in vivo, and postmortem study. J Neurotrauma. 2008;25(6):581-91.

41. Frugier T, Morganti-Kossmann MC, O'Reilly D, McLean CA. In situ detection of inflammatory mediators in post mortem human brain tissue after traumatic injury. J Neurotrauma. 2010;27(3):497-507.

42. Arcuri C, Mecca C, Bianchi R, Giambanco I, Donato R. The pathophysiological role of microglia in dynamic surveillance, phagocytosis and structural remodeling of the developing CNS. Front Mol Neurosci. 2017; 10:191.

43. Zhang F, Dong H, Lv T, Jin K, Jin Y, Zhang $X$, et al. Moderate hypothermia inhibits microglial activation after traumatic brain injury by modulating autophagy/apoptosis and the MyD88-dependent TLR4 signaling pathway. J Neuroinflammation. 2018;15(1):273.

44. Esen N, Kielian T. Central role for MyD88 in the responses of microglia to pathogenassociated molecular patterns. J Immunol. 2006;176(11):6802-11.

45. Karve IP, Taylor JM, Crack PJ. The contribution of astrocytes and microglia to traumatic brain injury. Br J Pharmacol. 2016;173(4):692-702.

46. Donat CK, Scott G, Gentleman SM, Sastre M. Microglial activation in traumatic brain injury. Front Aging Neurosci. 2017;9:208.

47. Loane DJ, Kumar A. Microglia in the TBI brain: the good, the bad, and the dysregulated. Exp Neurol. 2016;275 Pt 3(0 3):316-27.

48. Xu X, Yin D, Ren H, Gao W, Li F, Sun D, et al. Selective NLRP3 inflammasome inhibitor reduces neuroinflammation and improves long-term neurological outcomes in a murine model of traumatic brain injury. Neurobiol Dis. 2018; 117:15-27. 
49. O'Brien WT, Pham L, Symons GF, Monif M, Shultz SR, McDonald SJ. The NLRP3 inflammasome in traumatic brain injury: potential as a biomarker and therapeutic target. J Neuroinflammation. 2020;17(1):104.

50. Cherry JD, Olschowka JA, O'Banion MK. Neuroinflammation and M2 microglia: the good, the bad, and the inflamed. J Neuroinflammation. 2014; 11:98.

51. Seifert HA, Collier LA, Chapman CB, Benkovic SA, Willing AE, Pennypacker KR. Pro-inflammatory interferon gamma signaling is directly associated with stroke induced neurodegeneration. J Neurolmmune Pharmacol. 2014;9(5): 679-89.

52. Takaki J, Fujimori K, Miura M, Suzuki T, Sekino Y, Sato K. L-glutamate released from activated microglia downregulates astrocytic L-glutamate transporter expression in neuroinflammation: the 'collusion' hypothesis for increased extracellular L-glutamate concentration in neuroinflammation. J Neuroinflammation. 2012;9:275

53. Acosta SA, Tajiri N, Shinozuka K, Ishikawa H, Grimmig B, Diamond DM, et al. Long-term upregulation of inflammation and suppression of cell proliferation in the brain of adult rats exposed to traumatic brain injury using the controlled cortical impact model. PLoS One. 2013;8(1):e53376.

54. Aungst SL, Kabadi SV, Thompson SM, Stoica BA, Faden Al. Repeated mild traumatic brain injury causes chronic neuroinflammation, changes in hippocampal synaptic plasticity, and associated cognitive deficits. J Cereb Blood Flow Metab. 2014;34(7):1223-32.

55. Johnson VE, Stewart JE, Begbie FD, Trojanowski JQ, Smith DH, Stewart W. Inflammation and white matter degeneration persist for years after a single traumatic brain injury. Brain. 2013;136(Pt 1):28-42.

56. Mouzon BC, Bachmeier C, Ferro A, Ojo JO, Crynen G, Acker CM, et al. Chronic neuropathological and neurobehavioral changes in a repetitive mild traumatic brain injury model. Ann Neurol. 2014;75(2):241-54.

57. Ramlackhansingh AF, Brooks DJ, Greenwood RJ, Bose SK, Turkheimer FE, Kinnunen KM, et al. Inflammation after trauma: microglial activation and traumatic brain injury. Ann Neurol. 2011;70(3):374-83.

58. Smith C, Gentleman SM, Leclercq PD, Murray LS, Griffin WS, Graham DI, et al. The neuroinflammatory response in humans after traumatic brain injury. Neuropathol Appl Neurobiol. 2013;39(6):654-66.

59. Russo MV, McGavern DB. Inflammatory neuroprotection following traumatic brain injury. Science. 2016;353(6301):783-5.

60. Laird MD, Vender JR, Dhandapani KM. Opposing roles for reactive astrocytes following traumatic brain injury. Neurosignals. 2008;16(2-3):154-64.

61. Bush TG, Puvanachandra N, Horner CH, Polito A, Ostenfeld T, Svendsen CN, et al. Leukocyte infiltration, neuronal degeneration, and neurite outgrowth after ablation of scar-forming, reactive astrocytes in adult transgenic mice. Neuron. 1999:23(2):297-308.

62. Pedrazzi M, Patrone M, Passalacqua M, Ranzato E, Colamassaro D, Sparatore $B$, et al. Selective proinflammatory activation of astrocytes by high-mobility group box 1 protein signaling. J Immunol. 2007;179(12):8525-32.

63. Gorina R, Font-Nieves M, Márquez-Kisinousky L, Santalucia T, Planas AM. Astrocyte TLR4 activation induces a proinflammatory environment through the interplay between MyD88-dependent NFKB signaling, MAPK, and Jak1/ Stat1 pathways. Glia. 2011;59(2):242-55.

64. Shultz SR, Tan XL, Wright DK, Liu SJ, Semple BD, Johnston L, et al. Granulocyte-macrophage colony-stimulating factor is neuroprotective in experimental traumatic brain injury. J Neurotrauma. 2014;31(10):976-83.

65. Webster KM, Wright DK, Sun M, Semple BD, Ozturk E, Stein DG, et al. Progesterone treatment reduces neuroinflammation, oxidative stress and brain damage and improves long-term outcomes in a rat model of repeated mild traumatic brain injury. J Neuroinflammation. 2015;12:238.

66. Choi SS, Lee HJ, Lim I, Satoh J-I, Kim SU. Human astrocytes: secretome profiles of cytokines and chemokines. PLoS One. 2014;9(4):e92325.

67. Lau LT, Yu AC-H. Astrocytes produce and release interleukin-1, interleukin-6, tumor necrosis factor alpha and interferon-gamma following traumatic and metabolic injury. J Neurotrauma. 2001;18(3):351-9.

68. Zamanian JL, Xu L, Foo LC, Nouri N, Zhou L, Giffard RG, et al. Genomic analysis of reactive astrogliosis. J Neurosci. 2012;32(18):6391-410.

69. Gu Y, Zheng G, Xu M, Li Y, Chen X, Zhu W, et al. Caveolin-1 regulates nitric oxide-mediated matrix metalloproteinases activity and blood-brain barrier permeability in focal cerebral ischemia and reperfusion injury. J Neurochem. 2012;120(1):147-56.

70. Haorah J, Ramirez SH, Schall K, Smith D, Pandya R, Persidsky Y. Oxidative stress activates protein tyrosine kinase and matrix metalloproteinases leading to blood-brain barrier dysfunction. J Neurochem. 2007;101(2):566-76.
71. Semple BD, Kossmann T, Morganti-Kossmann MC. Role of chemokines in CNS health and pathology: a focus on the CCL2/CCR2 and CXCL8/CXCR2 networks. J Cereb Blood Flow Metab. 2010;30(3):459-73.

72. Makinde HM, Cuda CM, Just TB, Perlman HR, Schwulst SJ. Nonclassical monocytes mediate secondary injury, neurocognitive outcome, and neutrophi infiltration after traumatic brain injury. J Immunol. 2017;199(10):3583-91.

73. Liu Y-W, Li S, Dai S-S. Neutrophils in traumatic brain injury (TBI): friend or foe? J Neuroinflammation. 2018;15(1):146

74. Xie L, Poteet EC, Li W, Scott AE, Liu R, Wen Y, et al. Modulation of polymorphonuclear neutrophil functions by astrocytes. J Neuroinflammation. 2010;7:53.

75. Bao F, Shultz SR, Hepburn JD, Omana V, Weaver LC, Cain DP, et al. A CD11d monoclonal antibody treatment reduces tissue injury and improves neurological outcome after fluid percussion brain injury in rats. J Neurotrauma. 2012;29(14):2375-92.

76. Shultz SR, Bao F, Weaver LC, Cain DP, Brown A. Treatment with an antiCD11d integrin antibody reduces neuroinflammation and improves outcome in a rat model of repeated concussion. J Neuroinflammation. 2013;10:26.

77. Jin X, Ishii H, Bai Z, Itokazu T, Yamashita T. Temporal changes in cell marker expression and cellular infiltration in a controlled cortical impact model in adult male C57BL/6 mice. PLoS One. 2012;7(7):e41892.

78. Awasthi D, Church DF, Torbati D, Carey ME, Pryor WA. Oxidative stress following traumatic brain injury in rats. Surg Neurol. 1997;47(6):575-81.

79. Ritzel RM, Doran SJ, Barrett JP, Henry RJ, Ma EL, Faden Al, et al. Chronic alterations in systemic immune function after traumatic brain injury. J Neurotrauma. 2018;35(13):1419-36.

80. Ndode-Ekane XE, Matthiesen L, Banuelos-Cabrera I, Palminha CAP, Pitkanen A. T-cell infiltration into the perilesional cortex is long-lasting and associates with poor somatomotor recovery after experimental traumatic brain injury. Restor Neurol Neurosci. 2018;36(4):485-501.

81. Krämer TJ, Hack N, Brühl TJ, Menzel L, Hummel R, Griemert E-V, et al. Depletion of regulatory $T$ cells increases $T$ cell brain infiltration, reactive astrogliosis, and interferon- $\gamma$ gene expression in acute experimental traumatic brain injury. J Neuroinflammation. 2019;16(1):163.

82. Braun M, Vaibhav K, Saad N, Fatima S, Brann DW, Vender JR, et al. Activation of myeloid TLR4 mediates T lymphocyte polarization after traumatic brain injury. J Immunol. 2017:198(9):3615-26.

83. Spencer NG, Schilling T, Miralles F, Eder C. Mechanisms underlying interferon-gamma-induced priming of microglial reactive oxygen species production. PLoS One. 2016;11(9):e0162497.

84. Vergara D, Nigro A, Romano A, De Domenico S, Damato M, Franck J, et al Distinct protein expression networks are activated in microglia cells after stimulation with IFN- $\gamma$ and IL-4. Cells. 2019;8(6):580.

85. Rock RB, Hu S, Deshpande A, Munir S, May BJ, Baker CA, et al. Transcriptional response of human microglial cells to interferon-gamma. Genes Immun. 2005:6(8):712-9.

86. Yang $Y$, Ye $Y$, Chen C, Kong C, Su X, Zhang X, et al. Acute traumatic brain injury induces CD4+ and CD8+ T cell functional impairment by upregulating the expression of PD-1 via the activated sympathetic nervous system. Neuroimmunomodulation. 2019;26(1):43-57.

87. Blennow K, Hardy J, Zetterberg H. The Neuropathology and neurobiology of traumatic brain injury. Neuron. 2012;76(5):886-99.

88. Eakin K, Miller JP. Mild traumatic brain injury is associated with impaired hippocampal spatiotemporal representation in the absence of histological changes. J Neurotrauma. 2012;29(6):1180-7.

89. Ouyang W, Yan Q, Zhang Y, Fan Z. Moderate injury in motor-sensory cortex causes behavioral deficits accompanied by electrophysiological changes in mice adulthood. PLoS One. 2017;12(2):e0171976.

90. Popovitz J, Mysore SP, Adwanikar H. Long-term effects of traumatic brain injury on anxiety-like behaviors in mice: behavioral and neural correlates. Front Behav Neurosci. 2019:13:6.

91. Semple BD, Zamani A, Rayner G, Shultz SR, Jones NC. Affective, neurocognitive and psychosocial disorders associated with traumatic brain injury and post-traumatic epilepsy. Neurobiol Dis. 2019;123:27-41.

92. Clausen F, Hanell A, Israelsson C, Hedin J, Ebendal T, Mir AK, et al. Neutralization of interleukin-1 beta reduces cerebral edema and tissue loss and improves late cognitive outcome following traumatic brain injury in mice. Eur J Neurosci. 2011;34(1):110-23.

93. Dean PJ, Sterr A. Long-term effects of mild traumatic brain injury on cognitive performance. Front Hum Neurosci. 2013;7:30. 
94. Khuman J, Meehan WP 3rd, Zhu X, Qiu J, Hoffmann U, Zhang J, et al. Tumor necrosis factor alpha and Fas receptor contribute to cognitive deficits independent of cell death after concussive traumatic brain injury in mice. J Cereb Blood Flow Metab. 2011;31(2):778-89.

95. Ciaramella A, Della Vedova C, Salani F, Viganotti M, D'Ippolito M, Caltagirone C, et al. Increased levels of serum IL-18 are associated with the long-term outcome of severe traumatic brain injury. Neuroimmunomodulation. 2014; 21(1):8-12.

96. Sun Y, Bai L, Niu X, Wang Z, Yin B, Bai G, et al. Elevated serum levels of inflammation-related cytokines in mild traumatic brain injury are associated with cognitive performance. Front Neurol. 2019;10:1120.

97. Kenney K, lacono D, Edlow BL, Katz DI, Diaz-Arrastia R, Dams-O'Connor K, et al. Dementia after moderate-severe traumatic brain injury: coexistence of multiple proteinopathies. J Neuropathol Exp Neurol. 2018;77(1):50-63.

98. Sun L, Zhao M, Zhang J, Liu A, Ji W, Li Y, et al. MiR-144 promotes $\beta$-amyloid accumulation-induced cognitive impairments by targeting ADAM10 following traumatic brain injury. Oncotarget. 2017;8(35):59181-203.

99. Yang ST, Hsiao IT, Hsieh CJ, Chiang YH, Yen TC, Chiu WT, et al. Accumulation of amyloid in cognitive impairment after mild traumatic brain injury. J Neurol Sci. 2015;349(1-2):99-104.

100. Yoshiyama Y, Uryu K, Higuchi M, Longhi L, Hoover R, Fujimoto S, et al. Enhanced neurofibrillary tangle formation, cerebral atrophy, and cognitive deficits induced by repetitive mild brain injury in a transgenic tauopathy mouse model. J Neurotrauma. 2005;22(10):1134-41.

101. Li K, Wei Q, Liu FF, Hu F, Xie AJ, Zhu LQ, et al. Synaptic dysfunction in Alzheimer's disease: $A \beta, T a u$, and epigenetic alterations. Mol Neurobiol. 2018;55(4):3021-32.

102. Fenn AM, Gensel JC, Huang Y, Popovich PG, Lifshitz J, Godbout JP. Immune activation promotes depression 1 month after diffuse brain injury: a role for primed microglia. Biol Psychiatry. 2014;76(7):575-84.

103. Almeida-Suhett CP, Prager EM, Pidoplichko V, Figueiredo TH, Marini AM, Li Z, et al. Reduced GABAergic inhibition in the basolateral amygdala and the development of anxiety-like behaviors after mild traumatic brain injury. PLoS One. 2014;9(7):e102627.

104. Rao V, Lyketsos CG. Psychiatric aspects of traumatic brain injury. Psychiatr Clin North Am. 2002;25(1):43-69.

105. Wood RL, O'Hagan G, Williams C, McCabe M, Chadwick N. Anxiety sensitivity and alexithymia as mediators of postconcussion syndrome following mild traumatic brain injury. J Head Trauma Rehabil. 2014;29(1):E9-E17.

106. Truitt WA, Johnson PL, Dietrich AD, Fitz SD, Shekhar A. Anxiety-like behavior is modulated by a discrete subpopulation of interneurons in the basolateral amygdala. Neuroscience. 2009;160(2):284-94.

107. Sharma R, Leung WL, Zamani A, O'Brien TJ, Casillas Espinosa PM, Semple BD. Neuroinflammation in post-traumatic epilepsy: pathophysiology and tractable therapeutic targets. Brain Sci. 2019;9(11):318.

108. Balosso S, Liu J, Bianchi ME, Vezzani A. Disulfide-containing high mobility group box-1 promotes $\mathrm{N}$-methyl-D-aspartate receptor function and excitotoxicity by activating Toll-like receptor 4-dependent signaling in hippocampal neurons. Antioxid Redox Signal. 2014;21(12):1726-40.

109. Nikolic L, Shen W, Nobili P, Virenque A, Ulmann L, Audinat E. Blocking TNFadriven astrocyte purinergic signaling restores normal synaptic activity during epileptogenesis. Glia. 2018;66(12):2673-83.

110. Samland H, Huitron-Resendiz S, Masliah E, Criado J, Henriksen SJ, Campbell IL. Profound increase in sensitivity to glutamatergic- but not cholinergic agonist-induced seizures in transgenic mice with astrocyte production of IL6. J Neurosci Res. 2003;73(2):176-87.

111. Maroso M, Balosso S, Ravizza T, Liu J, Aronica E, lyer AM, et al. Toll-like receptor 4 and high-mobility group box-1 are involved in ictogenesis and can be targeted to reduce seizures. Nat Med. 2010;16(4):413-9.

112. Zhu G, Okada M, Yoshida S, Mori F, Ueno S, Wakabayashi K, et al. Effects of interleukin-1 beta on hippocampal glutamate and GABA releases associated with Ca2+-induced Ca2+ releasing systems. Epilepsy Res. 2006:71(2-3):107-16.

113. Proescholdt MG, Chakravarty S, Foster JA, Foti SB, Briley EM, Herkenham M. Intracerebroventricular but not intravenous interleukin-1 $\beta$ induces widespread vascular-mediated leukocyte infiltration and immune signal mRNA expression followed by brain-wide glial activation. Neuroscience. 2002;112(3):731-49.

114. Dubey JP. The history of Toxoplasma gondii--the first 100 years. J Eukaryot Microbiol. 2008:55(6):467-75.

115. Pappas G, Roussos N, Falagas ME. Toxoplasmosis snapshots: global status of Toxoplasma gondii seroprevalence and implications for pregnancy and congenital toxoplasmosis. Int J Parasitol. 2009;39(12):1385-94.
116. Gargaté MJ, Ferreira I, Vilares A, Martins S, Cardoso C, Silva S, et al. Toxoplasma gondii seroprevalence in the Portuguese population: comparison of three cross-sectional studies spanning three decades. BMJ Open. 2016;6(10):e011648.

117. John LN, McBride WJ, Millan J, Wilson K. Seroprevalence of anti-Toxoplasma gondii antibodies in HIV/AIDS patients and healthy blood donors at the Port Moresby General Hospital, Papua New Guinea. P N G Med J. 2012;55(14):88-93.

118. Singh S, Munawwar A, Rao S, Mehta S, Hazarika NK. Serologic prevalence of Toxoplasma gondii in Indian women of child bearing age and effects of social and environmental factors. PLoS Negl Trop Dis. 2014;8(3):e2737.

119. Burrells A, Opsteegh M, Pollock KG, Alexander CL, Chatterton J, Evans R, et al. The prevalence and genotypic analysis of Toxoplasma gondii from individuals in Scotland, 2006-2012. Parasit Vectors. 2016;9(1):324.

120. Wilking $H$, Thamm M, Stark K, Aebischer T, Seeber F. Prevalence, incidence estimations, and risk factors of Toxoplasma gondii infection in Germany: a representative, cross-sectional, serological study. Sci Rep. 2016:6:22551.

121. Dong H, Su R, Lu Y, Wang M, Liu J, Jian F, et al. Prevalence, risk factors, and genotypes of Toxoplasma gondii in food animals and humans (2000-2017) from China. Front Microbiol. 2018;9:2108.

122. Jones JL, Kruszon-Moran D, Elder S, Rivera HN, Press C, Montoya JG, et al. Toxoplasma gondii infection in the United States, 2011-2014. Am J Trop Med Hyg. 2018;98(2):551-7.

123. Shuralev EA, Shamaev ND, Mukminov MN, Nagamune K, Taniguchi Y, Saito T, et al. Toxoplasma gondii seroprevalence in goats, cats and humans in Russia. Parasitol Int. 2018;67(2):112-4.

124. Mareze M, Benitez AN, Brandão APD, Pinto-Ferreira F, Miura AC, Martins FDC, et al. Socioeconomic vulnerability associated to Toxoplasma gondii exposure in southern Brazil. PLoS One. 2019;14(2):e0212375.

125. Ramírez AM, Ríos YK, Galvis NF, Entrena E, Mariño NV, Rangel DM, et al. Seroprevalence and molecular detection of Toxoplasma gondii among donors in a blood bank in Cúcuta, Colombia. Biomedica. 2019;39(Supl. 2): 144-56.

126. Rouatbi M, Amairia S, Amdouni Y, Boussaadoun MA, Ayadi O, Al-Hosary AAT, et al. Toxoplasma gondii infection and toxoplasmosis in North Africa: a review. Parasite. 2019;26:6

127. Retmanasari A, Widartono BS, Wijayanti MA, Artama WT. Prevalence and risk factors for toxoplasmosis in Middle Java, Indonesia. EcoHealth. 2017;14(1): $162-70$.

128. Li X-L, Wei H-X, Zhang H, Peng H-J, Lindsay DS. A meta analysis on risks of adverse pregnancy outcomes in Toxoplasma gondii infection. PLoS One. 2014;9(5):e97775.

129. Sa Q, Ochiai E, Sengoku T, Wilson ME, Brogli M, Crutcher S, et al. VCAM-1/ a4 $\beta 1$ integrin interaction is crucial for prompt recruitment of immune $T$ cells into the brain during the early stage of reactivation of chronic infection with Toxoplasma gondii to prevent toxoplasmic encephalitis. Infect Immun. 2014:82(7):2826-39.

130. Pradhan S, Yadav R, Mishra VN. Toxoplasma meningoencephalitis in HIVseronegative patients: clinical patterns, imaging features and treatment outcome. Trans R Soc Trop Med Hyg. 2007;101(1):25-33.

131. Wang Z-D, Liu H-H, Ma Z-X, Ma H-Y, Li Z-Y, Yang Z-B, et al. Toxoplasma gondii infection in immunocompromised patients: a systematic review and meta-analysis. Front Microbiol. 2017:8:389.

132. Galván-Ramírez ML, Sánchez-Orozco LV, Gutiérrez-Maldonado AF, Rodriguez Pérez LR. Does Toxoplasma gondii infection impact liver transplantation outcomes? A systematic review. J Med Microbiol. 2018;67(4):499-506.

133. Flegr J. Influence of latent Toxoplasma infection on human personality, physiology and morphology: pros and cons of the Toxoplasma-human model in studying the manipulation hypothesis. J Exp Biol. 2013;216(Pt 1): 127-33.

134. Tyebji S, Seizova S, Hannan AJ, Tonkin CJ. Toxoplasmosis: a pathway to neuropsychiatric disorders. Neurosci Biobehav Rev. 2019;96:72-92.

135. Sutterland AL, Fond G, Kuin A, Koeter MWJ, Lutter R, van Gool T, et al. Beyond the association. Toxoplasma gondii in schizophrenia, bipolar disorder, and addiction: systematic review and meta-analysis. Acta Psychiatr Scand. 2015;132(3):161-79.

136. Deng Y, Wu T, Zhai S-Q, Li C-H. Recent progress on anti-Toxoplasma drugs discovery: design, synthesis and screening. Eur J Med Chem. 2019;183:111711.

137. Wang J-L, Zhang N-Z, Li T-T, He J-J, Elsheikha HM, Zhu X-Q. Advances in the development of anti-Toxoplasma gondii vaccines: challenges, opportunities, and perspectives. Trends Parasitol. 2019;35(3):239-53. 
138. Jensen KD, Camejo A, Melo MB, Cordeiro C, Julien L, Grotenbreg GM, et al. Toxoplasma gondii superinfection and virulence during secondary infection correlate with the exact ROP5/ROP18 allelic combination. mBio. 2015;6(2): e02280.

139. Xia J, Cheng X-Y, Wang X-J, Peng H-J. Association between Toxoplasma gondii types and outcomes of human infection: a meta-analysis. Acta Microbiol Immunol Hung. 2017;64(3):229-44.

140. Hosseini SA, Amouei A, Sharif M, Sarvi S, Galal L, Javidnia J, et al. Human toxoplasmosis: a systematic review for genetic diversity of Toxoplasma gondii in clinical samples. Epidemiol Infect. 2018;147:1-9.

141. Sibley LD, Khan A, Ajioka JW, Rosenthal BM. Genetic diversity of Toxoplasma gondii in animals and humans. Philos Trans R Soc Lond Ser B Biol Sci. 2009; 364(1530):2749-61.

142. Howe DK, Sibley LD. Toxoplasma gondii comprises three clonal lineages: correlation of parasite genotype with human disease. J Infect Dis. 1995; 172(6):1561-6

143. Pappoe F, Cheng W, Wang L, Li Y, Obiri-Yeboah D, Nuvor SV, et al. Prevalence of Toxoplasma gondii infection in HIV-infected patients and food animals and direct genotyping of T. gondii isolates, Southern Ghana. Parasitol Res. 2017;116(6):1675-85.

144. Lehmann T, Marcet PL, Graham DH, Dahl ER, Dubey JP. Globalization and the population structure of Toxoplasma gondii. Proc Natl Acad Sci U S A. 2006;103(30):11423-8.

145. Chaichan P, Mercier A, Galal L, Mahittikorn A, Ariey F, Morand S, et al. Geographical distribution of Toxoplasma gondii genotypes in Asia: A link with neighboring continents. Infect Genet Evol. 2017;53:227-38.

146. Galal L, Ajzenberg D, Hamidović A, Durieux M-F, Dardé M-L, Mercier A. Toxoplasma and Africa: one parasite, two opposite population structures. Trends Parasitol. 2018;34(2):140-54.

147. Frénal K, Dubremetz J-F, Lebrun M, Soldati-Favre D. Gliding motility powers invasion and egress in Apicomplexa. Nat Rev Microbiol. 2017;15(11):645-60.

148. Shapiro K, Bahia-Oliveira L, Dixon B, Dumètre A, de Wit LA, VanWormer E, et al. Environmental transmission of Toxoplasma gondii: oocysts in water, soil and food. Food Waterborne Parasitol. 2019;15:e00049.

149. Chiang TY, Kuo MC, Chen CH, Yang JY, Kao CF, Ji DD, et al. Risk factors for acute Toxoplasma gondii diseases in Taiwan: a population-based casecontrol study. PLoS One. 2014;9(3):e90880.

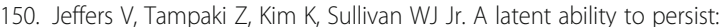
differentiation in Toxoplasma gondii. Cell Mol Life Sci. 2018;75(13):2355-73.

151. Buzoni-Gatel D, Werts C. Toxoplasma gondii and subversion of the immune system. Trends Parasitol. 2006;22(10):448-52.

152. Cook JH, Ueno N, Lodoen MB. Toxoplasma gondii disrupts beta1 integrin signaling and focal adhesion formation during monocyte hypermotility. J Biol Chem. 2018;293(9):3374-85.

153. Drewry LL, Jones NG, Wang Q, Onken MD, Miller MJ, Sibley LD. The secreted kinase ROP17 promotes Toxoplasma gondii dissemination by hijacking monocyte tissue migration. Nat Microbiol. 2019:4(11):1951-63.

154. Kanatani S, Uhlen P, Barragan A. Infection by Toxoplasma gondii induces amoeboid-like migration of dendritic cells in a three-dimensional collagen matrix. PLoS One. 2015;10(9):e0139104.

155. Sangaré LO, Ólafsson EB, Wang Y, Yang N, Julien L, Camejo A, et al. In vivo CRISPR screen identifies TgWIP as a Toxoplasma modulator of dendritic cell migration. Cell Host Microbe. 2019:26(4):478-92.e8.

156. Coffey MJ, Sleebs BE, Uboldi AD, Garnham A, Franco M, Marino ND, et al. An aspartyl protease defines a novel pathway for export of Toxoplasma proteins into the host cell. eLife. 2015;4:e10809.

157. Franco M, Panas MW, Marino ND, Lee M-CW, Buchholz KR, Kelly FD, et al. A novel secreted protein, MYR1, is central to toxoplasma's manipulation of host cells. mBio. 2016;7(1):e02231-15.

158. Hakimi MA, Olias P, Sibley LD. Toxoplasma effectors targeting host signaling and transcription. Clin Microbiol Rev. 2017;30(3):615-45.

159. Hammoudi P-M, Jacot D, Mueller C, Di Cristina M, Dogga SK, Marq J-B, et al. Fundamental roles of the golgi-associated toxoplasma aspartyl protease, ASP5, at the host-parasite interface. PLoS Pathog. 2015;11(10):e1005211.

160. Rastogi S, Cygan AM, Boothroyd JC. Translocation of effector proteins into host cells by Toxoplasma gondii. Curr Opin Microbiol. 2019:52:130-8.

161. Drewry LL, Sibley LD. The hitchhiker's guide to parasite dissemination. Cell Microbiol. 2019;21(11):e13070.

162. Harker KS, Jivan E, McWhorter FY, Liu WF, Lodoen MB. Shear forces enhance Toxoplasma gondii tachyzoite motility on vascular endothelium. mBio. 2014; 5(2):e01111-3.
163. Konradt C, Ueno N, Christian DA, Delong JH, Pritchard GH, Herz J, et al. Endothelial cells are a replicative niche for entry of Toxoplasma gondii to the central nervous system. Nat Microbiol. 2016;1(3):16001.

164. Lachenmaier SM, Deli MA, Meissner M, Liesenfeld O. Intracellular transport of Toxoplasma gondii through the blood-brain barrier. J Neuroimmunol. 2011;232(1-2):119-30.

165. Yarovinsky F. Innate immunity to Toxoplasma gondii infection. Nat Rev Immunol. 2014;14(2):109-21.

166. Mun HS, Aosai F, Norose K, Chen M, Piao LX, Takeuchi O, et al. TLR2 as an essential molecule for protective immunity against Toxoplasma gondii infection. Int Immunol. 2003;15(9):1081-7.

167. Debierre-Grockiego F, Campos MA, Azzouz N, Schmidt J, Bieker U, Resende MG, et al. Activation of TLR2 and TLR4 by glycosylphosphatidylinositols derived from Toxoplasma gondii. J Immunol. 2007;179(2):1129-37.

168. Denkers EY, Butcher BA, Del Rio L, Bennouna S. Neutrophils, dendritic cells and Toxoplasma. Int J Parasitol. 2004;34(3):411-21.

169. Hatai H, Lepelley A, Zeng W, Hayden MS, Ghosh S. Toll-like receptor 11 (TLR11) interacts with flagellin and profilin through disparate mechanisms. PLoS One. 2016:11(2):e0148987.

170. Plattner F, Yarovinsky F, Romero S, Didry D, Carlier M-F, Sher A, et al. Toxoplasma profilin is essential for host cell invasion and TLR11-dependent induction of an interleukin-12 response. Cell Host Microbe. 2008;3(2):77-87.

171. Scanga CA, Aliberti J, Jankovic D, Tilloy F, Bennouna S, Denkers EY, et al. Cutting edge: MyD88 is required for resistance to Toxoplasma gondii infection and regulates parasite-induced IL-12 production by dendritic cells. J Immunol. 2002;168(12):5997-6001.

172. Pifer R, Yarovinsky F. Innate responses to Toxoplasma gondii in mice and humans. Trends Parasitol. 2011:27(9):388-93.

173. Deckert-Schlüter $M$, Albrecht $S$, Hof H, Wiestler OD, Schlüter D. Dynamics of the intracerebral and splenic cytokine mRNA production in Toxoplasma gondii-resistant and -susceptible congenic strains of mice. Immunology. 1995:85(3):408-18.

174. Suzuki Y, Sa Q, Gehman M, Ochiai E. Interferon-gamma- and perforinmediated immune responses for resistance against Toxoplasma gondii in the brain. Expert Rev Mol Med. 2011;13:e31.

175. Nathan CF, Murray HW, Wiebe ME, Rubin BY. Identification of interferongamma as the lymphokine that activates human macrophage oxidative metabolism and antimicrobial activity. J Exp Med. 1983;158(3):670-89.

176. Pfefferkorn ER. Interferon gamma blocks the growth of Toxoplasma gondii in human fibroblasts by inducing the host cells to degrade tryptophan. Proc Natl Acad Sci U S A. 1984;81(3):908-12.

177. Pfefferkorn ER, Eckel M, Rebhun S. Interferon-gamma suppresses the growth of Toxoplasma gondii in human fibroblasts through starvation for tryptophan. Mol Biochem Parasitol. 1986;20(3):215-24.

178. Dellacasa-Lindberg I, Fuks JM, Arrighi RBG, Lambert H, Wallin RPA, Chambers BJ, et al. Migratory activation of primary cortical microglia upon infection with Toxoplasma gondii. Infect Immun. 2011;79(8):3046-52.

179. Landrith TA, Harris TH, Wilson EH. Characteristics and critical function of CD8+ T cells in the Toxoplasma-infected brain. Semin Immunopathol. 2015; 37(3):261-70.

180. Ploix CC, Noor S, Crane J, Masek K, Carter W, Lo DD, et al. CNS-derived CCL21 is both sufficient to drive homeostatic CD4+ T cell proliferation and necessary for efficient CD4+ T cell migration into the CNS parenchyma following Toxoplasma gondii infection. Brain Behav Immun. 2011;25(5):883-96.

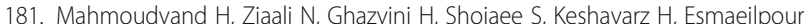
$K$, et al. Toxoplasma gondii infection promotes neuroinflammation through cytokine networks and induced hyperalgesia in BALB/C mice. Inflammation. 2016;39(1):405-12

182. Denkers EY, Gazzinelli RT. Regulation and function of T-cell-mediated immunity during Toxoplasma gondii infection. Clin Microbiol Rev. 1998; 11(4):569-88.

183. Di Cristina M, Marocco D, Galizi R, Proietti C, Spaccapelo R, Crisanti A. Temporal and spatial distribution of Toxoplasma gondii differentiation into Bradyzoites and tissue cyst formation in vivo. Infect Immun. 2008;76(8): 3491-501.

184. Cabral CM, Tuladhar S, Dietrich HK, Nguyen E, MacDonald WR, Trivedi T, et al. Neurons are the primary target cell for the brain-tropic intracellular parasite Toxoplasma gondii. PLoS Pathog. 2016:12(2):e1005447.

185. Koshy AA, Dietrich HK, Christian DA, Melehani JH, Shastri AJ, Hunter CA, et al. Toxoplasma Co-opts host cells it does not invade. PLoS Pathog. 2012; 8(7):e1002825 
186. Krishnamurthy S, Saeij JPJ. Toxoplasma does not secrete the GRA16 and GRA24 effectors beyond the parasitophorous vacuole membrane of tissue cysts. Front Cell Infect Microbiol. 2018;8:366.

187. Mayoral J, Shamamian P, Weiss LM. In vitro characterization of protein effector export in the bradyzoite stage of Toxoplasma gondii. mBio. 2020; 11(2):e00046-20.

188. Hwang YS, Shin J-H, Yang J-P, Jung B-K, Lee SH, Shin E-H. Characteristics of infection immunity regulated by toxoplasma gondii to maintain chronic infection in the brain. Front Immunol. 2018;9:158.

189. David CN, Frias ES, Szu JI, Vieira PA, Hubbard JA, Lovelace J, et al. GLT-1dependent disruption of CNS glutamate homeostasis and neuronal function by the protozoan parasite toxoplasma gondii. PLoS Pathog. 2016;12(6): e1005643

190. Alsaady I, Tedford E, Alsaad M, Bristow G, Kohli S, Murray M, et al. Downregulation of the central noradrenergic system by Toxoplasma gondii Infection. Infect Immun. 2019;87(2).

191. Gaskell EA, Smith JE, Pinney JW, Westhead DR, McConkey GA. A unique dual activity amino acid hydroxylase in Toxoplasma gondii. PLoS One. 2009; 4(3):e4801.

192. Wang ZT, Harmon S, O'Malley KL, Sibley LD. Reassessment of the role of aromatic amino acid hydroxylases and the effect of infection by Toxoplasma gondii on host dopamine. Infect Immun. 2015;83(3):1039-47.

193. McConkey GA, Peers C, Prandovszky E. Reproducing increased dopamine with infection to evaluate the role of parasite-encoded tyrosine hydroxylase activity. Infect Immun. 2015;83(8):3334.

194. Prandovszky E, Gaskell E, Martin H, Dubey JP, Webster JP, McConkey GA. The neurotropic parasite Toxoplasma gondii increases dopamine metabolism. PLoS One. 2011;6(9):e23866.

195. Ihara F, Nishimura M, Muroi Y, Mahmoud ME, Yokoyama N, Nagamune K, et al. Toxoplasma gondii infection in mice impairs long-term fear memory consolidation through dysfunction of the cortex and amygdala. Infect Immun. 2016;84(10):2861-70.

196. Kannan G, Crawford JA, Yang C, Gressitt KL, Ihenatu C, Krasnova IN, et al Anti-NMDA receptor autoantibodies and associated neurobehaviora pathology in mice are dependent on age of first exposure to Toxoplasma gondii. Neurobiol Dis. 2016;91:307-14.

197. Parlog A, Schluter D, Dunay IR. Toxoplasma gondii-induced neuronal alterations. Parasite Immunol. 2015:37(3):159-70.

198. Parlog A, Harsan L-A, Zagrebelsky M, Weller M, von Elverfeldt D, Mawrin C, et al. Chronic murine toxoplasmosis is defined by subtle changes in neuronal connectivity. Dis Model Mech. 2014;7(4):459-69.

199. Estato V, Stipursky J, Gomes F, Mergener TC, Frazao-Teixeira E, Allodi S, et al. The neurotropic parasite toxoplasma gondii induces sustained neuroinflammation with microvascular dysfunction in infected mice. Am J Pathol. 2018;188(11):2674-87.

200. Worth AR, Thompson RA, Lymbery AJ. Reevaluating the evidence for Toxoplasma gondii-induced behavioural changes in rodents. Adv Parasitol. 2014:85:109-42

201. Martinez VO, de Mendonça Lima FW, de Carvalho CF, Menezes-Filho JA. Toxoplasma gondii infection and behavioral outcomes in humans: a systematic review. Parasitol Res. 2018;117(10):3059-65.

202. Gulinello M, Acquarone M, Kim JH, Spray DC, Barbosa HS, Sellers R, et al. Acquired infection with Toxoplasma gondii in adult mice results in sensorimotor deficits but normal cognitive behavior despite widespread brain pathology. Microbes Infect. 2010;12(7):528-37.

203. Mahmoudvand H, Sheibani V, Keshavarz H, Shojaee S, Esmaeelpour K, Ziaali N. Acetylcholinesterase inhibitor improves learning and memory impairment induced by Toxoplasma gondii infection. Iran J Parasitol. 2016 11(2):177-85.

204. Daniels BP, Sestito SR, Rouse ST. An expanded task battery in the Morris water maze reveals effects of Toxoplasma gondii infection on learning and memory in rats. Parasitol Int. 2015;64(1):5-12.

205. Kannan G, Moldovan K, Xiao JC, Yolken RH, Jones-Brando L, Pletnikov MV. Toxoplasma gondii strain-dependent effects on mouse behaviour. Folia Parasitol. 2010;57(2):151-5.

206. Watson GF, Davis PH. Systematic review and meta-analysis of variation in Toxoplasma gondii cyst burden in the murine model. Exp Parasitol. 2019; 196:55-62.

207. Xiao J, Kannan G, Jones-Brando L, Brannock C, Krasnova IN, Cadet JL, et al. Sex-specific changes in gene expression and behavior induced by chronic Toxoplasma infection in mice. Neuroscience. 2012;206:39-48.
208. Mahmoudvand H, Sheibani V, Shojaee S, Mirbadie SR, Keshavarz H, Esmaeelpour $\mathrm{K}$, et al. Toxoplasma gondii infection potentiates cognitive impairments of Alzheimer's disease in the BALB/c Mice. J Parasitol. 2016; 102(6):629-35.

209. Gatkowska J, Wieczorek M, Dziadek B, Dzitko K, Dlugonska H. Behavioral changes in mice caused by Toxoplasma gondii invasion of brain. Parasitol Res. 2012;111(1):53-8.

210. Mahmoud ME, Fereig R, Nishikawa Y. Involvement of host defense mechanisms against Toxoplasma gondii infection in anhedonic and despairlike behaviors in mice. Infect Immun. 2017;85(4):e00007-17.

211. Tyebji S, Seizova S, Garnham AL, Hannan AJ, Tonkin CJ. Impaired social behaviour and molecular mediators of associated neural circuits during chronic Toxoplasma gondii infection in female mice. Brain Behav Immun. 2019;80:88-108

212. Bay-Richter C, Petersen E, Liebenberg N, Elfving B, Wegener G. Latent toxoplasmosis aggravates anxiety- and depressive-like behaviour and suggest a role of gene-environment interactions in the behavioural response to the parasite. Behav Brain Res. 2019;364:133-9.

213. Gonzalez LE, Rojnik B, Urrea F, Urdaneta H, Petrosino P, Colasante C, et al. Toxoplasma gondii infection lower anxiety as measured in the plus-maze and social interaction tests in rats: a behavioral analysis. Behav Brain Res. 2007;177(1):70-9.

214. Bay-Richter C, Buttenschøn HN, Mors O, Eskelund A, Budac D, Kærlev L, et al. Latent toxoplasmosis and psychiatric symptoms - a role of tryptophan metabolism? J Psychiatr Res. 2019;110:45-50.

215. Gale SD, Brown BL, Berrett A, Erickson LD, Hedges DW. Association between latent toxoplasmosis and major depression, generalised anxiety disorder and panic disorder in human adults. Folia Parasitol. 2014;61(4):285-92.

216. Mahmoud ME, Ihara F, Fereig RM, Nishimura M, Nishikawa Y. Induction of depression-related behaviors by reactivation of chronic Toxoplasma gondii infection in mice. Behav Brain Res. 2016;298(Pt B):125-33.

217. Notarangelo FM, Wilson EH, Horning KJ, Thomas MAR, Harris TH, Fang Q, et al. Evaluation of kynurenine pathway metabolism in Toxoplasma gondii-infected mice: implications for schizophrenia. Schizophr Res. 2014;152(1):261-7.

218. Wang T, Tang Z-H, Li J-F, Li X-N, Wang X, Zhao Z-J. A potential association between Toxoplasma gondii infection and schizophrenia in mouse models. Exp Parasitol. 2013;135(3):497-502.

219. Ngô HM, Zhou Y, Lorenzi H, Wang K, Kim TK, Zhou Y, et al. Toxoplasma modulates signature pathways of human epilepsy, neurodegeneration \& cancer. Sci Rep. 2017;7(1):11496.

220. Nayeri Chegeni T, Sarvi S, Moosazadeh M, Sharif M, Aghayan SA, Amouei A, et al. Is Toxoplasma gondii a potential risk factor for Alzheimer's disease? A systematic review and meta-analysis. Microb Pathog. 2019;137:103751.

221. Torres L, Robinson S-A, Kim D-G, Yan A, Cleland TA, Bynoe MS. Toxoplasma gondii alters NMDAR signaling and induces signs of Alzheimer's disease in wild-type, C57BL/6 mice. J Neuroinflammation. 2018;15(1):57.

222. Babaie J, Sayyah M, Choopani S, Asgari T, Golkar M, Gharagozli K. Toxoplasmosis accelerates acquisition of epilepsy in rats undergoing chemical kindling. Epilepsy Res. 2017;135:137-42.

223. Alvarado-Esquivel C, Rico-Almochantaf YDR, Hernández-Tinoco J, QuiñonesCanales G, Sánchez-Anguiano LF, Torres-González J, et al. Toxoplasma gondii exposure and epilepsy: a matched case-control study in a public hospital in northern Mexico. SAGE Ppen Med. 2018:6:2050312118767767.

224. Zheng P, Shultz SR, Hovens CM, Velakoulis D, Jones NC, O'Brien TJ. Hyperphosphorylated tau is implicated in acquired epilepsy and neuropsychiatric comorbidities. Mol Neurobiol. 2014;49(3):1532-9.

225. Möhle L, Israel N, Paarmann K, Krohn M, Pietkiewicz S, Müller A, et al. Chronic Toxoplasma gondii infection enhances $\beta$-amyloid phagocytosis and clearance by recruited monocytes. Acta Neuropathol Commun. 2016;4:25.

226. Liang Z, Liu F, Iqbal K, Grundke-lqbal I, Gong C-X. Dysregulation of tau phosphorylation in mouse brain during excitotoxic damage. J Alzheimers Dis. 2009;17(3):531-9.

227. Shultz SR, Jones NC, Zheng P, Liu S-J, O'Brien TJ, Wright DK, et al. Sodium selenate reduces hyperphosphorylated tau and improves outcomes after traumatic brain injury. Brain. 2015;138(5):1297-313.

228. Broussard JI, Acion L, De Jesús-Cortés H, Yin T, Britt JK, Salas R, et al. Repeated mild traumatic brain injury produces neuroinflammation, anxiety-like behaviour and impaired spatial memory in mice. Brain Inj. 2018;32(1):113-22.

229. Lively S, Schlichter LC. Microglia responses to pro-inflammatory stimuli (LPS, IFNy+TNFa) and reprogramming by resolving cytokines (IL-4, IL-10). Front Cell Neurosci. 2018;12:215. 
230. Taylor AN, Rahman SU, Sanders NC, Tio DL, Prolo P, Sutton RL. Injury severity differentially affects short- and long-term neuroendocrine outcomes of traumatic brain injury. J Neurotrauma. 2008;25(4):311-23.

231. Tümer N, Svetlov S, Whidden M, Kirichenko N, Prima V, Erdos B, et al. Overpressure blast-wave induced brain injury elevates oxidative stress in the hypothalamus and catecholamine biosynthesis in the rat adrenal medulla. Neurosci Lett. 2013;544:62-7.

232. Lu J, Goh SJ, Tng PY, Deng YY, Ling EA, Moochhala S. Systemic inflammatory response following acute traumatic brain injury. Front Biosci (Landmark Ed). 2009;14:3795-813.

233. Schaeffer M, Han S-J, Chtanova T, van Dooren GG, Herzmark P, Chen Y, et al. Dynamic imaging of $T$ cell-parasite interactions in the brains of mice chronically infected with Toxoplasma gondii. J Immunol. 2009;182(10):6379-93.

234. Rao VL, Baskaya MK, Dogan A, Rothstein JD, Dempsey RJ. Traumatic brain injury down-regulates glial glutamate transporter (GLT-1 and GLAST) proteins in rat brain. J Neurochem. 1998;70(5):2020-7.

235. Kierans AS, Kirov II, Gonen O, Haemer G, Nisenbaum E, Babb JS, et al. Myoinositol and glutamate complex neurometabolite abnormality after mild traumatic brain injury. Neurology. 2014;82(6):521-8.

236. Zhang $H$, Zhang $X$, Zhang $T$, Chen L. Excitatory amino acids in cerebrospinal fluid of patients with acute head injuries. Clin Chem. 2001;47(8):1458-62

237. Meaney DF, Smith DH. Biomechanics of concussion. Clin Sports Med. 2011; 30(1):19-vii.

238. Dincel GC, Atmaca HT. Role of oxidative stress in the pathophysiology of Toxoplasma gondii infection. Int J Immunopathol Pharmacol. 2016;29(2): 226-40.

239. Ansari MA, Roberts KN, Scheff SW. A time course of contusion-induced oxidative stress and synaptic proteins in cortex in a rat model of TBI. J Neurotrauma. 2008;25(5):513-26.

240. Obermeier B, Daneman R, Ransohoff RM. Development, maintenance and disruption of the blood-brain barrier. Nat Med. 2013;19(12):1584-96.

241. Ji X, Liu W, Xie K, Liu W, Qu Y, Chao X, et al. Beneficial effects of hydrogen gas in a rat model of traumatic brain injury via reducing oxidative stress. Brain Res. 2010;1354:196-205.

242. Johnson VE, Stewart W, Smith DH. Widespread $\tau$ and amyloid- $\beta$ pathology many years after a single traumatic brain injury in humans. Brain Pathol. 2012;22(2):142-9

243. Ułamek-Kozioł M, Czuczwar SJ, Januszewski S, Pluta R. Proteomic and genomic changes in tau protein, which are associated with Alzheimer's disease after ischemia-reperfusion brain injury. Int J Mol Sci. 2020;21(3):892

244. Dietrich HH, Xiang C, Han BH, Zipfel GJ, Holtzman DM. Soluble amyloidbeta, effect on cerebral arteriolar regulation and vascular cells. Mol Neurodegener. 2010;5:15

245. Ngoungou EB, Bhalla D, Nzoghe A, Darde ML, Preux PM. Toxoplasmosis and epilepsy—systematic review and meta analysis. PLoS Negl Trop Dis. 2015; 9(2):e0003525.

246. Villapol S, Loane DJ, Burns MP. Sexual dimorphism in the inflammatory response to traumatic brain injury. Glia. 2017;65(9):1423-38.

247. Doran SJ, Ritzel RM, Glaser EP, Henry RJ, Faden Al, Loane DJ. Sex differences in acute neuroinflammation after experimental traumatic brain injury are mediated by infiltrating myeloid cells. J Neurotrauma. 2019;36(7):1040-53.

248. Gupte R, Brooks W, Vukas R, Pierce J, Harris J. Sex differences in traumatic brain injury: what we know and what we should know. J Neurotrauma. 2019;36(22):3063-91.

249. Yue JK, Levin HS, Suen CG, Morrissey MR, Runyon SJ, Winkler EA, et al. Age and sex-mediated differences in six-month outcomes after mild traumatic brain injury in young adults: a TRACK-TBI study. Neurol Res. 2019;41(7):609-23.

250. Ritzel RM, Doran SJ, Glase EP, Meadows VE, Faden Al, Stoica BA, et al. Old age increases microglial senescence, exacerbates secondary neuroinflammation, and worsens neurological outcomes after acute traumatic brain injury in mice. Neurobiol Aging. 2019;77:194-206.

251. Sun M, Brady RD, Casillas-Espinosa PM, Wright DK, Semple BD, Kim HA, et al. Aged rats have an altered immune response and worse outcomes after traumatic brain injury. Brain Behav Immun. 2019;80:536-50.

252. Sun M, McDonald SJ, Brady RD, Collins-Praino L, Yamakawa GR, Monif M, et al. The need to incorporate aged animals into the preclinical modeling of neurological conditions. Neurosci Biobehav Rev. 2020;109:114-28.

253. Brady RD, Casillas-Espinosa PM, Agoston DV, Bertram EH, Kamnaksh A, Semple BD, et al. Modelling traumatic brain injury and posttraumatic epilepsy in rodents. Neurobiol Dis. 2019;123:8-19.
254. Kuwar R, Rolfe A, Di L, Xu H, He L, Jiang $Y$, et al. A novel small molecular NLRP3 inflammasome inhibitor alleviates neuroinflammatory response following traumatic brain injury. J Neuroinflammation. 2019; 16(1):81.

255. Gov L, Schneider CA, Lima TS, Pandori W, Lodoen MB. NLRP3 and potassium efflux drive rapid IL-1 $\beta$ release from primary human monocytes during Toxoplasma gondii infection. J Immunol. 2017;199(8):2855-64.

256. Helmy A, Guilfoyle MR, Carpenter KLH, Pickard JD, Menon DK, Hutchinson PJ. Recombinant human interleukin-1 receptor antagonist in severe traumatic brain injury: a phase II randomized control trial. J Cereb Blood Flow Metab. 2014;34(5):845-51.

257. Sun M, Brady RD, Wright DK, Kim HA, Zhang SR, Sobey CG, et al. Treatment with an interleukin-1 receptor antagonist mitigates neuroinflammation and brain damage after polytrauma. Brain Behav Immun. 2017:66:359-71.

258. Shultz SR, Sun M, Wright DK, Brady RD, Liu S, Beynon S, et al. Tibial fracture exacerbates traumatic brain injury outcomes and neuroinflammation in a novel mouse model of multitrauma. J Cereb Blood Flow Metab. 2015;35(8):1339-47.

259. Martynowicz J, Augusto L, Wek RC, Boehm SL, Sullivan WJ. Guanabenz reverses a key behavioral change caused by latent toxoplasmosis in mice by reducing neuroinflammation. mBio. 2019;10(2):e00381-19.

260. Takigawa S, Chen A, Nishimura A, Liu S, Li B-Y, Sudo A, et al. Guanabenz Downregulates Inflammatory Responses via elF2a Dependent and Independent Signaling. Int J Mol Sci. 2016;17(5):674.

261. Benmerzouga I, Checkley LA, Ferdig MT, Arrizabalaga G, Wek RC, Sullivan WJ Jr. Guanabenz repurposed as an antiparasitic with activity against acute and latent toxoplasmosis. Antimicrob Agents Chemother. 2015;59(11):6939-45.

262. Hood KN, Zhao J, Redell JB, Hylin MJ, Harris B, Perez A, et al. Endoplasmic reticulum stress contributes to the loss of newborn hippocampal neurons after traumatic brain injury. J Neurosci. 2018;38(9):2372-84.

263. Dash PK, Hylin MJ, Hood KN, Orsi SA, Zhao J, Redell JB, et al. Inhibition of eukaryotic initiation factor 2 alpha phosphatase reduces tissue damage and improves learning and memory after experimental traumatic brain injury. J Neurotrauma. 2015;32(20):1608-20.

264. Francis GS. Modulation of peripheral sympathetic nerve transmission. J Am Coll Cardiol. 1988;12(1):250-4.

265. Konrad C, Queener SF, Wek RC, Sullivan WJ Jr. Inhibitors of elF2a dephosphorylation slow replication and stabilize latency in Toxoplasma gondii. Antimicrob Agents Chemother. 2013;57(4):1815-22.

266. Wang ZF, Gao C, Chen W, Gao Y, Wang HC, Meng Y, et al. Salubrinal offers neuroprotection through suppressing endoplasmic reticulum stress, autophagy and apoptosis in a mouse traumatic brain injury model. Neurobiol Learn Mem. 2019;161:12-25.

267. Dunay IR, Gajurel K, Dhakal R, Liesenfeld O, Montoya JG. Treatment of toxoplasmosis: historical perspective, animal models, and current clinical practice. Clin Microbiol Rev. 2018;31(4):e00057-17.

268. Gohardehi S, Sharif M, Sarvi S, Moosazadeh M, Alizadeh-Navaei R, Hosseini SA, et al. The potential risk of toxoplasmosis for traffic accidents: a systematic review and meta-analysis. Exp Parasitol. 2018;191:19-24.

269. Cook TB, Brenner LA, Cloninger CR, Langenberg P, Igbide A, Giegling I, et al. "Latent" infection with Toxoplasma gondii: association with trait aggression and impulsivity in healthy adults. J Psychiatr Res. 2015;60:87-94.

270. Mosti C, Coccaro EF. Mild traumatic brain injury and aggression, impulsivity, and history of other- and self-directed aggression. J Neuropsychiatr Clin Neurosci. 2018;30(3):220-7.

271. Taylor CA, Bell JM, Breiding MJ, Xu L. Traumatic brain injury-related emergency department visits, hospitalizations, and deaths-United States, 2007 and 2013. MMWR Surveill Summ. 2017;66(9):1-16.

272. Shaw AC, Goldstein DR, Montgomery RR. Age-dependent dysregulation of innate immunity. Nat Rev Immunol. 2013;13(12):875-87.

273. Zhang $Y-H$, Chen $H$, Chen Y, Wang L, Cai Y-H, Li M, et al. Activated microglia contribute to neuronal apoptosis in Toxoplasmic encephalitis. Parasit Vectors. 2014:7:372.

274. Doran SJ, Henry RJ, Shirey KA, Barrett JP, Ritzel RM, Lai W, et al. Early or late bacterial lung infection increases mortality after traumatic brain injury in male Mice and chronically impairs monocyte innate immune function. Crti Care Med. 2020;48(5):e418-28.

275. Hang CH, Shi JX, Tian J, Li JS, Wu W, Yin HX. Effect of systemic LPS injection on cortical NF-kappaB activity and inflammatory response following traumatic brain injury in rats. Brain Res. 2004;1026(1):23-32. 
276. Sharma R, Shultz SR, Robinson MJ, Belli A, Hibbs ML, O'Brien TJ, et al. Infections after a traumatic brain injury: The complex interplay between the immune and neurological systems. Brain Behav Immun. 2019;79:63-74.

277. McDonald SJ, Sharkey JM, Sun M, Kaukas LM, Shultz SR, Turner RJ, et al. Beyond the brain: peripheral interactions after traumatic brain injury. J Neurotrauma. 2020;37(5):770-81.

278. Weiss DJ, Lucas TCD, Nguyen M, Nandi AK, Bisanzio D, Battle KE, et al. Mapping the global prevalence, incidence, and mortality of Plasmodium falciparum, 2000-17: a spatial and temporal modelling study. Lancet. 2019; 394(10195):322-31.

279. Storm J, Craig AG. Pathogenesis of cerebral malaria-inflammation and cytoadherence. Front Cell Infect Microbiol. 2014;4:100.

280. Christensen SS, Eslick GD. Cerebral malaria as a risk factor for the development of epilepsy and other long-term neurological conditions: a meta-analysis. Trans R Soc Trop Med Hyg. 2015;109(4):233-8.

281. Ali I, Silva JC, Liu S, Shultz SR, Kwan P, Jones NC, O'Brien TJ. Targeting neurodegeneration to prevent post-traumatic epilepsy. Neurobiol Dis. 2019; 123:100-9.

282. Kennedy PGE, Rodgers J. Clinical and neuropathogenetic aspects of human African trypanosomiasis. Front Immunol. 2019;10:39.

283. Amin DN, Rottenberg ME, Thomsen AR, Mumba D, Fenger C, Kristensson K, et al. Expression and role of CXCL10 during the encephalitic stage of experimental and clinical African trypanosomiasis. J Infect Dis. 2009;200(10): 1556-65.

284. Amin DN, Vodnala SK, Masocha W, Sun B, Kristensson K, Rottenberg ME. Distinct Toll-like receptor signals regulate cerebral parasite load and interferon $\alpha / \beta$ and tumor necrosis factor $\alpha$-dependent T-cell infiltration in the brains of Trypanosoma brucei-infected mice. J Infect Dis. 2012;205(2): 320-32.

285. Wickwire EM, Schnyer DM, Germain A, Williams SG, Lettieri CJ, KcKeon AB, et al. Sleep, sleep disorders, and circadian health following mild traumatic brain injury in adults: review and research agenda. J Neurotrauma. 2018; 35(22):2615-31.

286. Córdova E, Maiolo E, Corti M, Orduña T. Neurological manifestations of Chagas' disease. Neurol Res. 2010;32(3):238-44

287. Montanaro WA, Hora TF, da Silva CM, de Viana Santos CV, Lima MIR, de Jesus Oliveira EM, et al. Epidemiology of concurrent Chagas disease and ischemic stroke in a population attending a multicenter quaternary rehabilitation network in Brazil. Neurol Sci. 2019:40(12):2595-601.

288. Coura JR, Borges-Pereira J. Chagas disease: 100 years after its discovery. A systemic review. Acta Trop. 2010;115(1-2):5-13.

\section{Publisher's Note}

Springer Nature remains neutral with regard to jurisdictional claims in published maps and institutional affiliations.

Ready to submit your research? Choose BMC and benefit from:

- fast, convenient online submission

- thorough peer review by experienced researchers in your field

- rapid publication on acceptance

- support for research data, including large and complex data types

- gold Open Access which fosters wider collaboration and increased citations

- maximum visibility for your research: over $100 \mathrm{M}$ website views per year

At $\mathrm{BMC}$, research is always in progress.

Learn more biomedcentral.com/submissions 